\title{
Global distribution of total ozone and lower stratospheric temperature variations
}

\author{
W. Steinbrecht ${ }^{1}$, B. Hassler ${ }^{1}$, H. Claude ${ }^{1}$, P. Winkler ${ }^{1}$, and R. S. Stolarski ${ }^{2}$ \\ ${ }^{1}$ German Weather Service, Hohenpeissenberg, Germany \\ ${ }^{2}$ NASA, Goddard Space Flight Center, Greenbelt, Maryland, USA
}

Received: 23 May 2003 - Published in Atmos. Chem. Phys. Discuss.: 3 July 2003

Revised: 10 September 2003 - Accepted: 15 September 2003 - Published: 22 September 2003

\begin{abstract}
This study gives an overview of interannual variations of total ozone and $50 \mathrm{hPa}$ temperature. It is based on newer and longer records from the 1979 to 2001 Total Ozone Monitoring Spectrometer (TOMS) and Solar Backscatter Ultraviolet (SBUV) instruments, and on US National Center for Environmental Prediction (NCEP) reanalyses. Multiple linear least squares regression is used to attribute variations to various natural and anthropogenic explanatory variables. Usually, maps of total ozone and $50 \mathrm{hPa}$ temperature variations look very similar, reflecting a very close coupling between the two. As a rule of thumb, a 10 Dobson Unit (DU) change in total ozone corresponds to a $1 \mathrm{~K}$ change of $50 \mathrm{hPa}$ temperature. Large variations come from the linear trend term, up to $-30 \mathrm{DU}$ or $-1.5 \mathrm{~K} / \mathrm{decade}$, from terms related to polar vortex strength, up to $50 \mathrm{DU}$ or $5 \mathrm{~K}$ (typical, minimum to maximum), from tropospheric meteorology, up to $30 \mathrm{DU}$ or $3 \mathrm{~K}$, or from the Quasi-Biennial Oscillation (QBO), up to $25 \mathrm{DU}$ or $2.5 \mathrm{~K}$. The 11-year solar cycle, up to $25 \mathrm{DU}$ or $2.5 \mathrm{~K}$, or El Niño/Southern Oscillation (ENSO), up to $10 \mathrm{DU}$ or $1 \mathrm{~K}$, are contributing smaller variations. Stratospheric aerosol after the 1991 Pinatubo eruption lead to warming up to $3 \mathrm{~K}$ at low latitudes and to ozone depletion up to $40 \mathrm{DU}$ at high latitudes. Variations attributed to QBO, polar vortex strength, and to a lesser degree to ENSO, exhibit an inverse correlation between low latitudes and higher latitudes. Variations related to the solar cycle or $400 \mathrm{hPa}$ temperature, however, have the same sign over most of the globe. Variations are usually zonally symmetric at low and mid-latitudes, but asymmetric at high latitudes. There, position and strength of the stratospheric anti-cyclones over the Aleutians and south of Australia appear to vary with the phases of solar cycle, QBO or ENSO.
\end{abstract}

Correspondence to: W. Steinbrecht

(wolfgang.steinbrecht@dwd.de)

\section{Introduction}

The discovery of the "ozone-hole" over Antarctica in 1984 has triggered enormous interest in stratospheric ozone, both from the general public and from the scientific community. Continuing improvement of our understanding of the various processes controlling the stratospheric ozone layer has since been documented by a wealth of publications (Solomon, 1999; Staehelin et al., 2001) and by a series of ozone assessments (SPARC, 1998; WMO, 2003). Production of harmful chlorofluorocarbons was successfully curbed by international agreements, i.e. the Vienna Convention for the Protection of the Ozone Layer (1985), the Montreal Protocol (1987) and its amendments. A reduction of chlorine loading and a recovery of the ozone layer are expected at some time in this century (Engel et al., 1998; WMO, 2003). However, stratospheric chlorine will remain high for the next years. Bromine, which also destroys ozone, is still increasing. The ozone layer will remain vulnerable. Many details of the expected ozone recovery are unclear, e.g. possible interactions with climate change, or the consequences of increasing bromine (Salby and Callaghan, 2002; Ramaswamy et al., 2001; WMO, 2003). In order to actually "see" a recovery, high quality measurements are needed for many years to come. For the early detection of signs of a recovery, or of a possible worsening, a good quantitative understanding is necessary for the various natural processes, which contribute to the variation of ozone levels from year to year.

Many studies have investigated variations of ozone and temperature on interannual time scales. This includes trends (Bojkov et al., 1990; Staehelin et al., 2001; Ramaswamy et al., 2001), as well as variations associated with the QBO (Yang and Tung, 1995; Baldwin et al., 2001), the 11-year solar cycle (Zerefos et al., 1997; Hood, 1997; Labitzke and van Loon, 2000; Lee and Smith, 2003), the El Niño/Southern Oscillation (ENSO) (Shiotani, 1992; Zerefos et al., 1992; Reid, 1994), or meteorological factors (Hood et al., 1999; Appenzeller et al., 2000; Steinbrecht et al., 2001). 
The purpose of this study is to give an updated and more global overview of the most relevant sources of variance. Newer and longer data records are used. Rather than focus on global means or zonal averages, the full geographical distribution is presented. A large fraction of the ozone column resides in the lower stratosphere where ozone and temperature are closely linked (Randel and Cobb, 1994). Therefore, analysis of the ozone column data is complemented by analysis of lower stratospheric temperature data, at $50 \mathrm{hPa}$. Where possible, a simple conceptual view is presented, linking total ozone and lower stratospheric temperature variations to a given influence.

\section{Data sources and method}

The investigation is based on total column ozone data from the series of Total Ozone Mapping Spectrometers (TOMS) and Solar Backscatter Ultraviolet (SBUV and SBUV/2) instruments on various satellite platforms. All data are calibrated to be consistent with the 1996 to 1999 Earth-Probe TOMS instrument. See Stolarski and Hollandsworth (2002) for details. The combined data-set currently provides nearly continuous global coverage from late 1978 to December 2001 , on a $5^{\circ}$ latitude, $10^{\circ}$ longitude grid. For each grid cell and each month of the year climatological mean values were defined by the average value over the entire 1979 to 2001 time period. Monthly mean total ozone anomalies were then calculated for each grid cell by subtracting the climatological mean value for the appropriate month of the year. The resulting anomaly time series are the basis of our investigation.

The same procedure was applied to lower stratospheric temperature fields at $50 \mathrm{hPa}$ from meteorological reanalyses by the US National Center for Environmental Prediction (NCEP, Kistler et al., 2001). The NCEP data were regridded to the same latitude-longitude grid as the TOMS/SBUV data. Here we generally report on NCEP data from the same 1979 to 2001 time period where TOMS/SBUV data are available. However, most of the results for $50 \mathrm{hPa}$ temperature change very little, when NCEP data for the longer 1958 to 2001 time period are analysed.

In order to quantify different contributions to total ozone or $50 \mathrm{hPa}$ temperature variations a multiple regression approach is employed (Steinbrecht et al., 2001). This has become standard practice (Bojkov et al., 1990; SPARC, 1998; WMO, 2003), but here more predictors are used, in particular meteorological parameters. Anomaly time series $Y$ of total ozone or $50 \mathrm{hPa}$ temperature are described as a linear combination of predictor time series (=explanatory variables), each of which accounts for a different contribution to total ozone or temperature variations:

$$
\begin{aligned}
Y= & c_{T R} T R+c_{F S} F S+c_{A} A+c_{T(400)} T(400) \\
& +c_{Q B O(10)} Q B O(10)+c_{Q B O(30)} Q B O(30) \\
& +c_{u(60 N)} u(60 N)+c_{u(60 S)} u(60 S) \\
& +c_{E N S O} E N S O+\text { residual }
\end{aligned}
$$

Given time series for the explanatory variables trend $T R$, solar cycle $F S$, stratospheric aerosol $A, 400 \mathrm{hPa}$ temperature anomaly $T(400)$, equatorial wind at 10 and $30 \mathrm{hPa}$ $Q B O(10 / 30)$, zonal wind anomaly at $60^{\circ}$ North and South, $u(60 N / S)$, and El Niño/Southern Oscillation, ENSO, as well as observed time series of ozone or temperature at each grid cell, $Y$, the coefficients $c_{\ldots .}$ can be determined by linear least squares regression. Global fields for each coefficient are obtained as a result. They describe the geographical distribution of the influence for each explanatory variable. Regression was done separately for seasonal mean anomalies, yielding separate sets of coefficients $c_{T R}, c_{F S}, c_{Q B O(10)}$, and so on, for winter (December, January , February $=$ DJF), spring (March, April, May = MAM), summer (June, July, August = JJA), and fall (September, October, November $=$ SON). Thus a seasonal variation is allowed for. From the "full" set of possible explanatory variables, only those contributing significantly, at the $90 \%$ confidence level of partial F-tests, were left in the regression, following the stepwise regression procedure outlined in Draper and Smith (1998).

Obviously Eq. (1) is only a very simple approximation. Non-linear effects, as well as possible couplings between explanatory variables, are neglected. Generally, only an "average" contribution from each predictor can be obtained. In some years a much stronger or much weaker actual contribution must be expected. Nevertheless, our results indicate that even this simple approach can still give quite a useful quantification. A more complete picture can be obtained, e.g. with 3-dimensional, fully coupled chemistry global-circulation model simulations. However, such simulations are much more complex and more difficult to interpret.

\subsection{Explanatory variables}

The choice of explanatory variables in Eq. (1) is based on the criteria that all should be relevant for total ozone from past experience, and that the data should be easy to obtain and should be updated regularly. The linear trend $T R$ describes long-term ozone changes related to the more or less linear increase of stratospheric chlorine since the 1970s. Most recent data show slowing chlorine increase, or very recently, even the beginnings of a decrease (WMO, 2003). However, for compatibility with many other studies, the linear increase was used as a good enough simple description. Improvements would be marginal, if a more detailed curve were used (Steinbrecht et al., 2001). For $50 \mathrm{hPa}$ temperature, the linear trend simply describes long-term changes.

$10.7 \mathrm{~cm}$ solar radio flux $F S$ is a common proxy for UV irradiance changes related to the 11-year solar cycle (Zerefos et al., 1997). Monthly mean data observed in Ottawa and Penticton, Canada, were obtained from ftp://ftp.ngdc.noaa. gov/STP/SOLAR_DATA/SOLAR_RADIO/FLUX. 
For variations related to the Quasi-Biennial Oscillation (QBO), equatorial zonal winds at 10 and $30 \mathrm{hPa} Q B O(10)$ and $Q B O(30)$ from FU Berlin are included (B. Naujokat, priv. comm. 2003). Correct phasing of the QBO related signal is allowed for by using winds at two levels, 10 and $30 \mathrm{hPa}$, which are out of phase by nearly $\pi / 2$ (see Bojkov and Fioletov, 1995).

Large enhancements of stratospheric aerosol after major volcanic eruptions in the tropics affect ozone and temperature by changing heating rates and atmospheric transports. Ozone is additionally affected by heterogeneous reactions on the much increased aerosol surface area (Solomon, 1999; Robock, 2000). To account for these effects, the time dependent stratospheric aerosol optical depth $A$ is included as one explanatory variable. We use zonal mean data compiled by Sato (2003), which allow for latitudinal variation. For the period of interest, the data are largely based on measurements by the Stratospheric Aerosol and Gas Experiments (SAGE I and II). Note that using stratospheric aerosol optical depth measured by lidar at a single location (GarmischPartenkirchen in Southern Germany) (Jäger et al., 1995) gives very similar results.

The meteorological situation in the troposphere can have a large influence on ozone column and on lower stratospheric temperature (Steinbrecht et al., 1998; Appenzeller et al., 2000). Therefore temperature anomalies at $400 \mathrm{hPa}, T(400)$, were used as one explanatory variable. Temperature in the free troposphere and lower stratosphere is highly correlated with other meteorological parameters such as tropopause height, geopotential heights, or tropospheric circulation indices. The $T(400)$ anomaly field was derived from NCEP reanalyses.

Influences from the El Niño-Southern Oscillation phenomenon are accounted for by the ENSO explanatory variable, obtained from the US National Oceanic and Atmospheric Administration, Climate Prediction Center (NOAACPC, http://www.cpc.ncep.noaa.gov/data/indices/).

The strength of the polar winter vortex is another important explanatory variable. A strong vortex is a prerequisite for the formation of an "ozone hole" (Solomon, 1999). Vortex strength is also related to meridional transports in the Brewer-Dobson circulation (Perlwitz and Graf, 1995; Salby and Callaghan, 2002). Zonal wind anomalies at $50 \mathrm{hPa}, 60^{\circ}$ North and $60^{\circ}$ South from NCEP reanalyses, $u(60 N / S)$, are a good measure of vortex strength, and were included as explanatory variables. Other possibilities are indices for the large scale stratospheric circulation, such as the Arctic Oscillation Index (Baldwin and Dunkerton, 1999), or the divergence of the Eliassen-Palm flux (Salby and Callaghan, 2002). However, we preferred the zonal-winds, because they are easy to obtain from the NCEP reanalyses and seem to work quite well.

\subsection{Technical aspects}

Linear least squares regression requires that the explanatory variables are sufficiently independent (uncorrelated). While we found that this is generally fulfilled in our case, there are two important exceptions: 1.) The strength of the polar vortex is related to the phase of the QBO and the solar cycle (Holton and Tan, 1980; Labitzke and van Loon, 2000). 2.) Tropospheric temperatures $T(400)$ are highly correlated with El Niño/La Niña over large parts of the globe. When two explanatory variables are highly correlated, the stepwise approach tends to include only the more significant explanatory variable, and leave the less significant explanatory variables out of the regression (Draper and Smith, 1998). This avoids technical problems with highly correlated explanatory variables. For the critical cases, results obtained with the full set of predictors are compared to results with a reduced set of predictors. Generally, interdependencies between the explanatory variables are small and hardly influence the results.

The residual in Eq. (1) is typically a first-order autocorrelated noise series (Bojkov et al., 1990; SPARC, 1998). However, since seasonal mean data are used, and since the regression usually describes a very large part of the observed variance, autocorrelation was found to be negligible. One years total ozone or temperature residual has little to do with the residual of the previous year. This simplifies the statistical tests and the stepwise linear regression model. Nevertheless, particularly for the solar cycle, it must be realized that the 23 years of 1979 to 2001 data only cover 3 solar maxima and 2 solar minima. Thus we have less than 23 completely independent samples of the solar cycle effect, but likely more than 3. The statistical significance, i.e. the confidence level, of our results may therefore be overestimated, in particular for the longer time-scales of solar cycle or ENSO. Since for $50 \mathrm{hPa}$ temperature very similar results are obtained when using 42 years of NCEP data (1958 to 2001), there does not seem to be a major problem.

\subsection{Data quality}

A detailed investigation of the data quality of the TOMS/SBUV or NCEP reanalysis data-sets is clearly beyond the scope of this paper. However, the following discussion indicates that there are no major inconsistencies in the two data-sets. Our results should, therefore, be representative for the "true" atmosphere.

For total ozone, Fioletov et al. (2002) and Harris et al. (2003) have compared various total ozone time series, from ground-based spectrometers, from an assimilated TOMS/GOME/ground-based data-set at NIWA (Bodeker et al., 2001), and from the TOMS/SBUV merged data-set used in this paper. For zonal means over large latitude bands, e.g. $35^{\circ} \mathrm{N}$ to $60^{\circ} \mathrm{N}$, Fioletov et al. (2002) report differences between these data sets that vary over time, but are generally less than $1 \%(\approx 2$ to 4 DU). Harris et al. (2003) only report on 


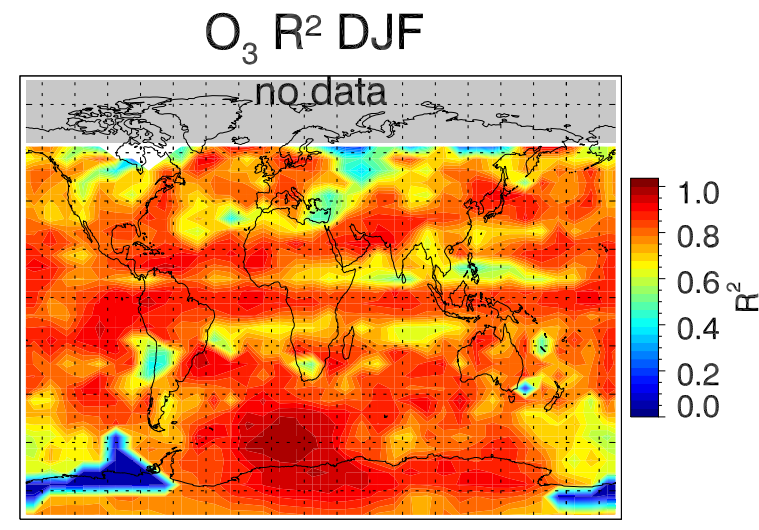

$\mathrm{O}_{3} \mathrm{R}^{2} \mathrm{SON}$

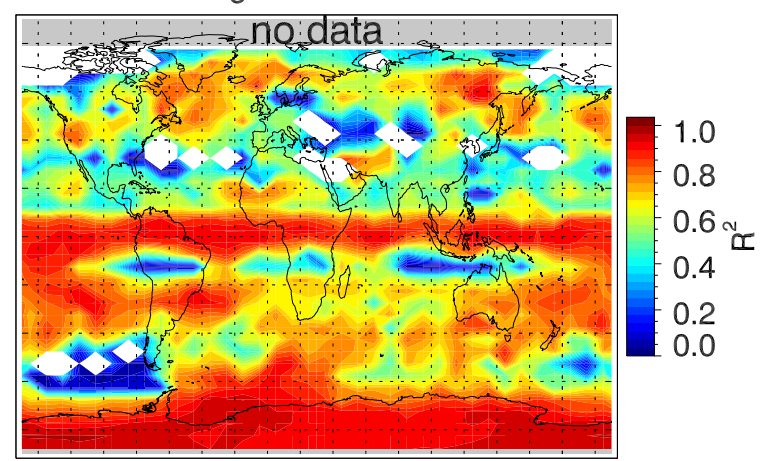

T50 R² DJF

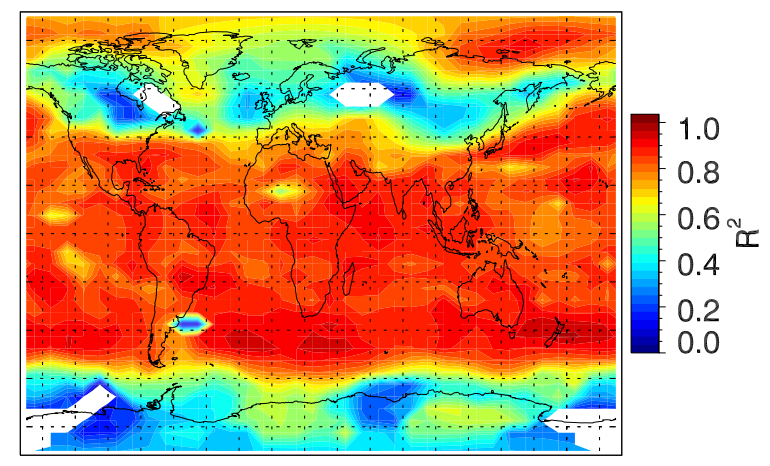

T50 R SON

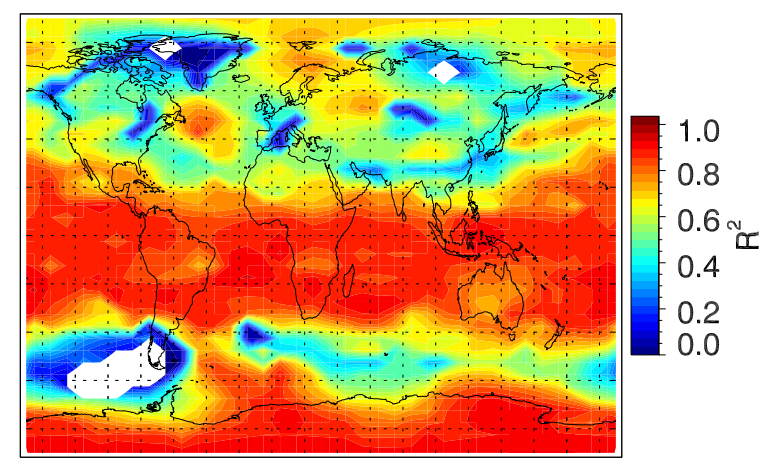

Fig. 1. Global maps of $R^{2}$ from regression of 1978 to 2001 TOMS/SBUV total ozone anomalies on a $5^{\circ}$ latitude by $10^{\circ}$ longitude grid (left panels), or of 1978 to $200150 \mathrm{hPa}$ temperature anomalies from NCEP reanalyses (right panels), for winter (DJF, top panels) and fall (SON, bottom panels). No TOMS/SBUV observations are available in polar regions in winter. The corresponding regions are indicated by grey shading.

low-pass filtered data, where most known sources of variability have been removed, such as solar-cycle, QBO, $500 \mathrm{hPa}$ temperature, etc.. They only consider fluctuations on timescales longer than the QBO, and do find a smaller longterm trend in the merged TOMS/SBUV data set. Apart from that, they find time varying differences between the data sets that are typically smaller than $1 \%$ for selected smaller regions, such as the grid cells used in our analysis. Time varying bias of the merged TOMS/SBUV data-set will certainly affect our results. However, based on Fioletov et al.'s and Harris et al.'s results, it seems that errors should be of the order of 1 to $2 \%$, corresponding to a few Dobson Units. This is comparable to the statistical uncertainty of our results, which is typically larger than 2 to $5 \mathrm{DU}$. Therefore we think that data consistency of the TOMS/SBUV data-set is not a major issue for our analysis.

The NCEP reanalysis data do exhibit quality changes over time which are related mostly to changes in the observing system. The largest known jumps in NCEP reanalyses occur at the introduction of satellite observations in late 1978 (Santer et al., 1999; Trenberth et al., 2001). Since our paper uses mainly the 1979 to 2001 data, it should not be affected by this major jump. Even when the extended 1958 to 2001 period (major jump in late 1978) is considered, nearly all of our results, except for the linear trend, are very similar to those obtained for the more homogeneous 1979 to 2001 period. We would expect that possible smaller quality changes after 1979 would result in even less noticable changes. Independent support for the case of the 11-year solar cycle comes from van Loon and Labitzke (1999), who found very similar results for NCEP reanalysis and Berlin stratospheric analyses for the 1968 to 1996 period, which includes the major jump in NCEP reanalyses.

\section{Results}

An important measure for the performance of a regression is $R^{2}$, the ratio of variance described by the regression, i.e. the variance of all terms on the right side of Eq. (1) except for the residual, to observed variance, i.e. to the variance of the left side of Eq. (1). A perfect regression has $R^{2}=1$ and fully explains the observed variance. Small $R^{2} \approx 0$ indicates 


\section{$\mathrm{O}_{3}$ lin_trend MAM}

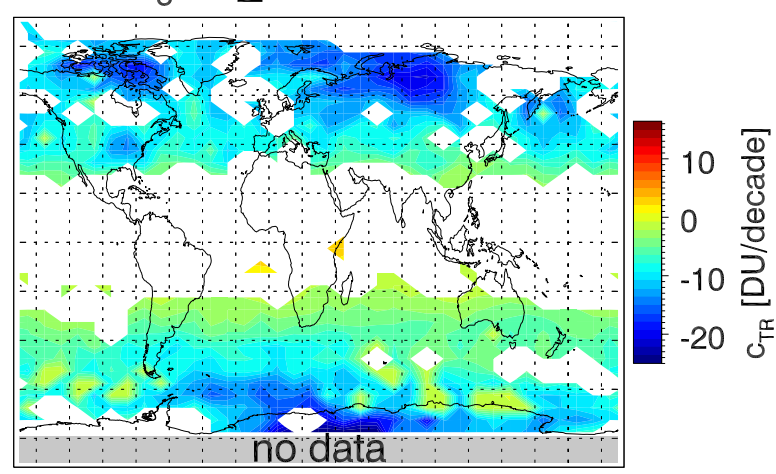

\section{$\mathrm{O}_{3}$ lin_trend SON}

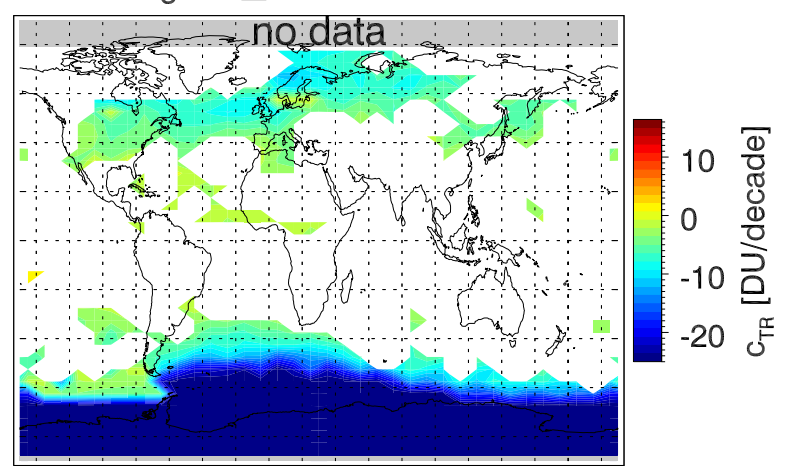

T50 lin_trend MAM

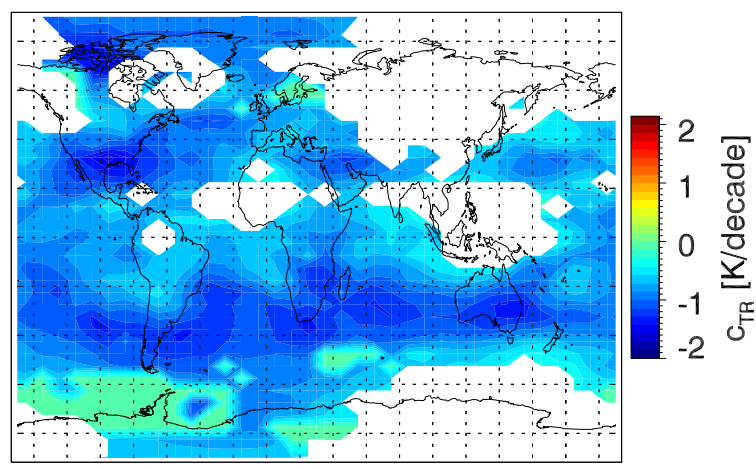

T50 lin_trend SON

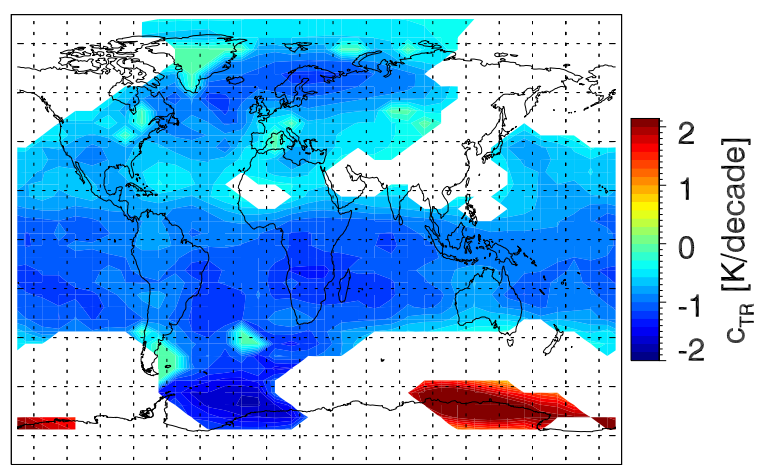

Fig. 2. Left panels: Linear trend, in DU per decade, from multiple regression of 1978 to $2001 \mathrm{TOMS} / \mathrm{SBUV}$ total ozone anomalies on a $5^{\circ}$ latitude by $10^{\circ}$ longitude grid. Right panels: Linear trend, in K per decade, from multiple regression of 1978 to 2001 temperature anomalies at $50 \mathrm{hPa}$ from NCEP reanalyses on a $5^{\circ}$ latitude by $10^{\circ}$ longitude grid. Top panels: Spring (MAM). Bottom panels: Fall (SON). In the white regions the linear trend is not statistically significant at the $90 \%$ confidence level. Also note that no TOMS/SBUV observations are available in polar regions in winter. The corresponding regions are indicated by grey shading.

that the regression explains only a small part of the observed variance. This can happen when random noise, e.g. from the measurement itself, accounts for a large fraction of the observed variance, or when important explanatory variables are missing. Generally for our study, $R^{2}$ values are higher in winter and spring, and lower in fall, in the respective hemispheres.

As examples for good and relatively poor regression, Fig. 1 shows maps of $R^{2}$ for Northern Hemisphere winter (DJF) and Northern Hemisphere fall (SON). In DJF, $R^{2}$ for total ozone exceeds 0.7 over most of the observed globe, indicating that more than 70 percent of the observed total ozone variance are accounted for by the regression. In some regions the regression works less well, e.g. around $10^{\circ}$ North and $10^{\circ}$ South, over parts of Russia, or over the Southern Pacific. Regression also works less well for SON, where $R^{2}$ falls below 0.4 for a substantial fraction of the Northern Hemisphere, and for some regions in the Southern Hemisphere. An important contributor to the low $R^{2}$ regions around $10^{\circ}$ latitude, on either side of the equator, is the low natural variance of total ozone there. This makes atmospheric and observa- tional noise more relevant. To a lesser degree the same applies to the lower $R^{2}$ over the fall hemispheres. The low $R^{2}$ regions over the Southern Pacific in Southern Hemisphere spring (SON), or over Russia in northern winter (DJF) are more pronounced in the $R^{2}$ maps for $50 \mathrm{hPa}$ temperature (right panels of Fig. 1).

For $50 \mathrm{hPa}$ temperature, $R^{2}$ is similar for all seasons. $R^{2}$ is high $(>0.7)$ and the regression works well in the tropics and subtropics and in the polar region in winter. However, there are broad bands around $50^{\circ}$ to $60^{\circ}$ latitude of each hemisphere where $R^{2}$ is low $(<0.4)$. There, the regression does not give a good description. To a lesser degree, these bands also appear in the $R^{2}$ for total ozone. These bands might come from variations in position and size of jet-streams or polar vortices, not well accounted for by the present set of explanatory variables. Additional explanatory variables might improve the regression in this latitude band. However, within the scope of the present study, simple additional explanatory variables could not be found. As a consequence, results for the $50^{\circ}$ to $60^{\circ}$ latitude bands have to be interpreted with care. 


\subsection{Linear trend}

Figure 2 shows maps of the linear trend term from Eq. (1) for northern and southern spring. This term describes longterm changes in total ozone, which can largely be attributed to chemical ozone depletion by anthropogenic chlorine and bromine (Staehelin et al., 2001; WMO, 2003). Total ozone has been decreasing over the last 20 years outside of the tropics. The decrease is larger at higher latitudes. In both hemispheres, the decrease is larger in spring than in fall. By far the largest ozone trends, up to -50 Dobson Units (DU) per decade, are found in the "ozone hole" south of $50^{\circ} \mathrm{S}$ in southern spring. Fairly high ozone trends, up to -20 DU/decade are also found in northern spring over Siberia. Trends for DJF and JJA (both not shown) are similar to those for MAM and SON, respectively.

Temperature at $50 \mathrm{hPa}$ also shows a significant negative trend over most of the globe, ranging between -0.5 and $-2 \mathrm{~K}$ per decade. The trend appears to be larger in the Southern Hemisphere, and is generally larger in the tropics and subtropics and in the summer and fall hemispheres. Note that the temperature trends exhibit less seasonal variation than the total ozone trends. Smaller negative temperature trends by 0.5 to $1 \mathrm{~K}$, with a similar geographical distribution are found when the regression is applied to NCEP reanalyses for the longer 1958 to 2001 period, not only the 1979 to 2001 period corresponding to the total ozone record.

The ozone trends presented here are fully consistent with other recent investigations, e.g. Fioletov et al. (2002), or WMO (2003). Note, however, that Harris et al. (2003), using a different method, find smaller trends for the same merged TOMS/SBUV data set. Apart from the region south of $60^{\circ} \mathrm{S}$, where the specific time period considered and questions regarding consistency of the NCEP reanalysis before 1979 appear to be important, our temperature trends are similar to Ramaswamy et al. (2001).

\subsection{Variations associated with tropospheric meteorology}

Temperature anomalies at $400 \mathrm{hPa}$ were included in the regression to account for links between tropospheric meteorological parameters and total ozone or lower stratospheric temperature (Steinbrecht et al., 1998; Appenzeller et al., 2000; WMO, 2003). Figure 3 shows the size of ozone and $50 \mathrm{hPa}$ temperature fluctuations linked to $T(400)$.

As size of the variation attributed to an explanatory variable $X$, here and in most following plots and discussions, we define 2 standard deviations $(2 \sigma)$ of the corresponding time series term $\left(c_{X} X\right)$ on the right side of Eq. (1). This size is close to the average minimum-to-maximum variation attributed to explanatory variable $X$. Using $2 \sigma$ allows an easy comparison of the importance of different explanatory variables. The color plots in Fig. 3, and the following, show this size as a function of latitude and longitude over the globe. Red and yellow colors indicate positive correlation between ozone, or temperature, and explanatory variable $X$. Blue colors (negative values) indicate inverse correlation. Note that for explanatory variables $X$ that do not vary with latitude or longitude, the second scales on the maps directly give the size of the regression coefficients $c_{X}$. For explanatory variables that vary over the map, notably $T_{400}$ and $A$, the second scales on the maps can only be approximate.

As Fig. 3 shows, both ozone and $50 \mathrm{hPa}$ temperature fluctuations are inversely correlated to tropospheric temperature. The size of the variations generally increases with latitude. In the tropics little or no ozone fluctuations are associated with tropospheric temperature changes. Variations associated with $400 \mathrm{hPa}$ temperature are largest in spring at northern high latitudes, where they reach up to $30 \mathrm{DU}$ or $3 \mathrm{~K}$. The overall picture is, however, similar for all seasons and both hemispheres. Total ozone is low and the lower stratosphere is cold when the troposphere is warm, whereas total ozone and lower stratospheric temperature are high when the troposphere is cold.

Part of this behavior can be explained by up- and downward air motions in the lower stratosphere, which compensate opposite vertical motions in the troposphere (Reed, 1950; Steinbrecht et al., 1998; Labitzke and van Loon, 1999). In a tropospheric high pressure system, sinking air in the troposphere leads to adiabatic warming there. The tropopause and air in the lower stratosphere rise. This results in adiabatic cooling in the lower stratosphere and moves ozone poor air up. Total ozone decreases. A tropospheric low pressure system has vertical motions in the opposite direction, and consequently a cold troposphere and a warm, ozone rich lower stratosphere with high total ozone. These vertical motions go hand in hand with horizontal advection, e.g. of ozone poor air from low latitudes, or of ozone rich air from high latitudes in the lower stratosphere (Salby and Callaghan, 1993; Koch et al., 2002). A typical low pressure system advects ozone poor low-latitude air above its tropospheric warm sector, where the tropopause is high, and advects ozone rich high-latitude air above its tropospheric cold sector, where the tropopause is low. Salby and Callaghan (1993) estimate that vertical motions account for about two thirds, and horizontal advection for about one third of the total ozone fluctuations directly associated with meteorology. Note that increased/decreased radiative heating by more/less ozone also tends to give a positive correlation between total ozone and lower stratospheric temperature, especially on longer time-scales (Ramaswamy et al., 2001).

\subsection{Influence of the Quasi-Biennial Oscillation}

The QBO with its downwards propagating zonal wind anomalies is an intriguing example of wave mean-flow interaction in the atmosphere. It has far-ranging effects that can be observed in many atmospheric parameters (Baldwin et al., 2001). Size and geographic distribution of ozone and $50 \mathrm{hPa}$ temperature fluctuations attributed to the QBO by the 


\section{$\mathrm{O}_{3} \mathrm{~T}_{-} 400 \mathrm{hPa} \mathrm{MAM}$}

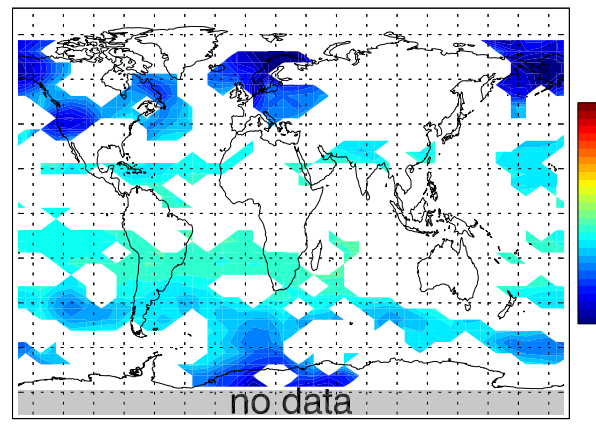

$\mathrm{O}_{3} \mathrm{~T}_{-} 400 \mathrm{hPa} \mathrm{SON}$

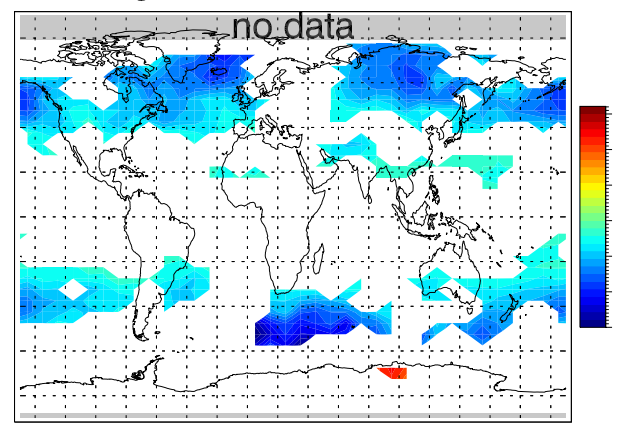

T50 T 400hPa MAM

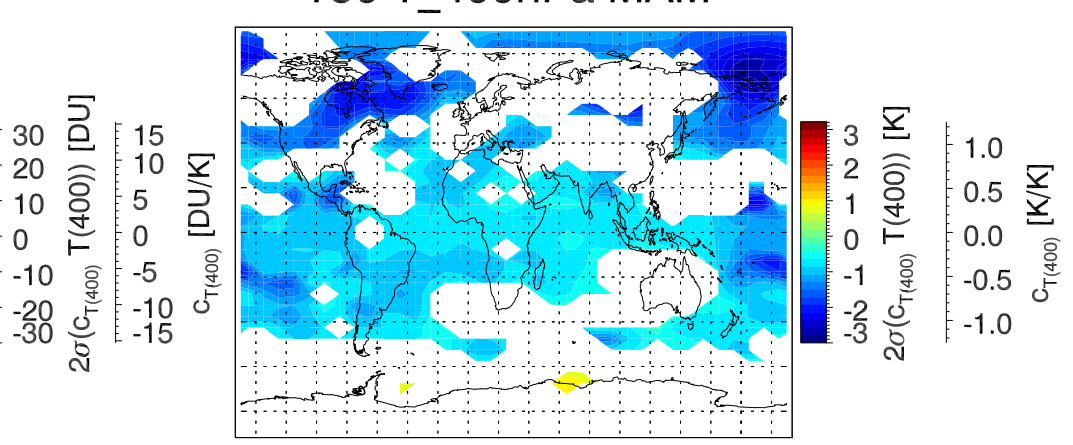

T50 T_400hPa SON

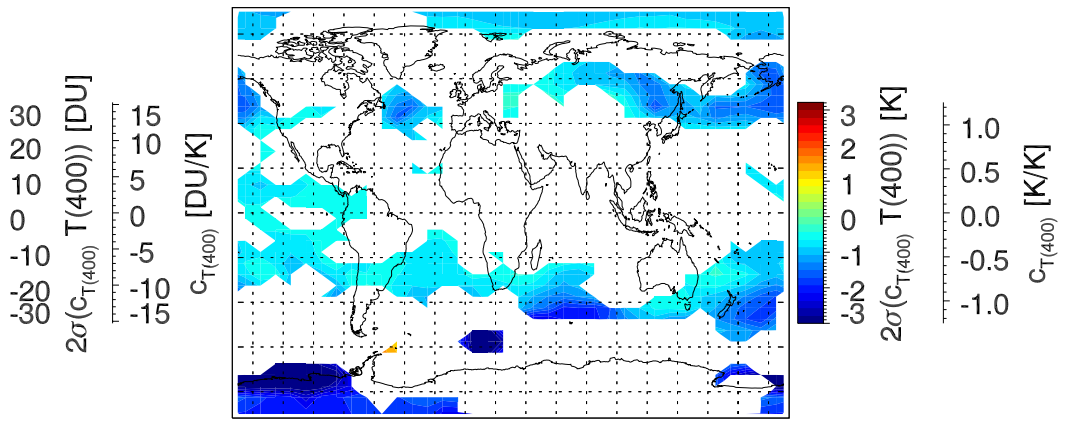

Fig. 3. Size of fluctuations attributed to temperature anomalies at $400 \mathrm{hPa}$. The size is defined as 2 standard deviations, in DU or K, of the term $c_{T(400)} T(400)$ in Eq. (1). The second scales, on the right, give only the approximate size of the regression coefficient $c_{T}(400)$. In this plot and the following, blue colors (negative values) indicate that ozone or temperature are inversely (negatively) correlated to the explanatory variable, whereas yellow and red colors (positive values) denote positive correlation. In the white regions the explanatory variable is not statistically significant at the $90 \%$ confidence level. Also note that no TOMS/SBUV observations are available in polar regions in winter. These regions are indicated by grey shading.

regression in this study are shown in Fig. 4. When equatorial zonal wind is westerly at $30 \mathrm{hPa}$, total ozone and $50 \mathrm{hPa}$ temperature are high in the tropics (yellow and red colors) and are low (green and blue colors) in a subtropical belt from about $20^{\circ}$ to $40^{\circ}$ or $50^{\circ}$. In the winter hemisphere, subtropical ozone and temperature anomalies are larger, up to $-25 \mathrm{DU}$ or $-2.5 \mathrm{~K}$, than in the summer hemisphere, where they only reach up to $-5 \mathrm{DU}$ or $-0.5 \mathrm{~K}$. Ozone anomalies in the summer hemisphere also extend to higher latitudes. Size, up to $25 \mathrm{DU}$ or $2.5 \mathrm{~K}$, and annual variation, much larger signal in the winter/spring hemisphere, of QBO related variations found here agree well with previous results summarized by Baldwin et al. (2001).

The tropical and subtropical anomalies can be explained by a QBO-induced residual circulation with descending/ascending motion in the tropics and ascending/descending motion in the subtropics (Andrews et al., 1987; Baldwin et al., 2001). This circulation modulates the stronger large-scale Brewer-Dobson circulation, which has an ascending branch in the tropics and descending branches in the extratropics. According to the thermal wind relation, the vertical motions of the QBO residual circulation are in- duced by the westerly/easterly vertical wind shear associated with the QBO. For the case of westerly wind shear, e.g. when maximum westerly winds are found at or above $30 \mathrm{hPa}$, the QBO induced circulation is downwards in the tropical lower stratosphere. This slows the general Brewer-Dobson upwelling in the tropics. Less ozone poor air is brought up in the tropical lower stratosphere, thereby increasing tropical total ozone. Less upwelling also means less adiabatic cooling and thus a warmer tropical lower stratosphere. It explains the yellow and red band of positive anomalies around the Equator in Fig. 4. In the subtropics the QBO induced circulation is upwards. The general downwelling of ozone rich air in the extratropics from the Brewer-Dobson circulation is reduced, thereby decreasing subtropical total ozone. Also, adiabatic heating of the subtropical lower stratosphere is reduced. These regions of decreased downwelling appear as blue bands in Fig. 4. In the winter hemisphere, the subtropical anomaly is enhanced by the strong residual Brewer-Dobson circulation in winter and spring (Baldwin et al., 2001).

While tropical and subtropical variations related to the QBO are zonally symmetric, QBO-related fluctuations at 
$\mathrm{O}_{3} \mathrm{QBO}$ DJF

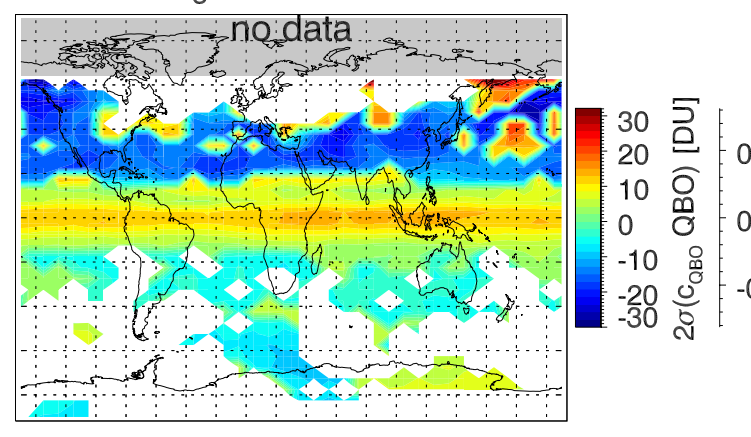

\section{$\mathrm{O}_{3} \mathrm{QBO} J J A$}

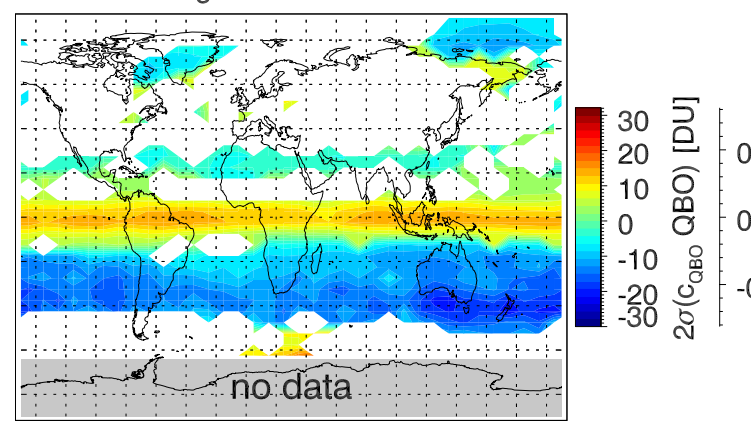

T50 QBO DJF

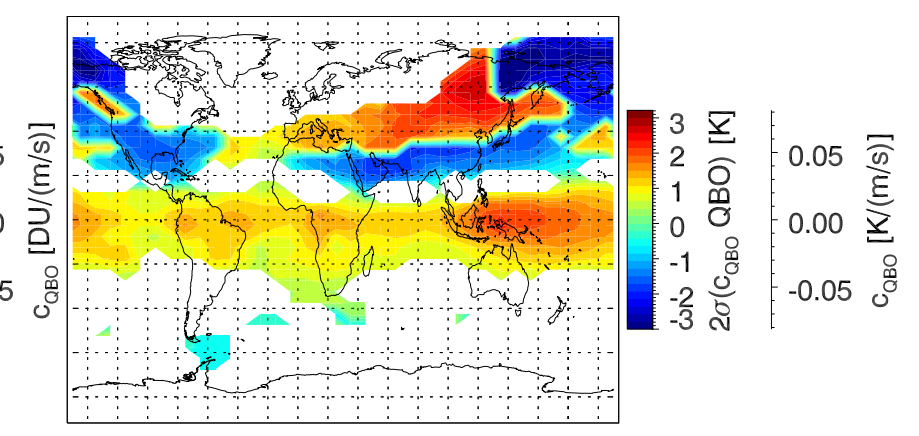

Fig. 4. Same as Fig. 3, but for fluctuations attributed to the QBO. The scales on the false color bars give 2 standard deviations (2 $\sigma$ ) of the QBO term $c_{Q B O(10)} Q B O(10)+c_{Q B O(30)} Q B O(30)$ in Eq. (1). The second scales, on the right, give the approximate size of the QBO regression coefficient $\sqrt{c_{Q B O(10)}^{2}+c_{Q B O(30)}^{2}}$. Blue colors indicate inverse (negative) correlation with westerly zonal wind at $30 \mathrm{hPa}$ at the Equator, whereas yellow and red colors indicate positive correlation.

higher latitudes in the winter hemispheres, between $40^{\circ}$ and $80^{\circ}$, are not zonally symmetric: High $50 \mathrm{hPa}$ temperatures, i.e. the red or yellow regions in Fig. 4 occur during QBOwesterlies at $30 \mathrm{hPa}$ from Europe to Northeastern Asia in DJF (and MAM, not shown), north of North-America in SON (not shown), and above the Southern Atlantic Ocean in JJA (and SON as well, not shown). Where TOMS/SBUV data are available, the total ozone maps also indicate variations in these regions. These higher latitude features are out of phase with the subtropical and in phase with the tropical signal. Phase changes in QBO-attributed variations at latitudes around $40^{\circ} \mathrm{N}$ or $50^{\circ} \mathrm{N}$ have been noted previously (Bojkov and Fioletov, 1995; Yang and Tung, 1995). Yang and Tung argued that phase changes appear because high-latitude total ozone anomalies in some years have the same sign as anomalies in mid-latitudes. In other years they have the opposite sign. When projected onto any QBO-predictor, these "missing" beats produce an apparent phase change. Irregular "missing" beats, not accounted for by the regression, would also create a band of low $R^{2}$, as seen in Fig. 1 .

Because of the inclusion of zonal wind anomalies at $60^{\circ}$, $50 \mathrm{hPa}$, as one explanatory variable in the regression (see Figs. 10 and 11), QBO modulations related to polar vortex strength do not appear in Fig. 4. Therefore, Fig. 5 shows results of a regression where trend, solar cycle and QBO were used as the only explanatory variables. For most seasons and latitudes, the QBO signal for this reduced set of explanatory variables is very similar to the $\mathrm{QBO}$ signal obtained with the full set of explanatory variables in Fig. 4. The main difference between the two sets of explanatory variables is a dipole between low polar temperatures north of $60^{\circ} \mathrm{N}$ and high temperatures in a band around $40^{\circ} \mathrm{N}$, that are seen in Fig. 5 for the reduced set of explanatory variables in DJF and SON (not shown), during QBO-westerlies at $30 \mathrm{hPa}$. Also, high temperatures and high total ozone around $40^{\circ}$ are more pronounced and more zonally symmetric in Fig. 5, compared to Fig. 4. As shown later in Fig. 10, such a see-saw between high and lower latitudes is the signature of polar vortex strength. Because the QBO modulates the strength of the polar vortex, parts of the variations related to polar vortex strength are taken over by the QBO explanatory variable, when no explanatory variable for polar vortex strength is included in the regression. This is the case for Fig. 5.

Colder polar temperatures and a stronger polar vortex during times of QBO-westerlies (e.g. at $30 \mathrm{hPa}$ ) are well documented (Holton and Tan, 1980). A strong polar vortex goes 
$\mathrm{O}_{3}$ QBO DJF (SQT)

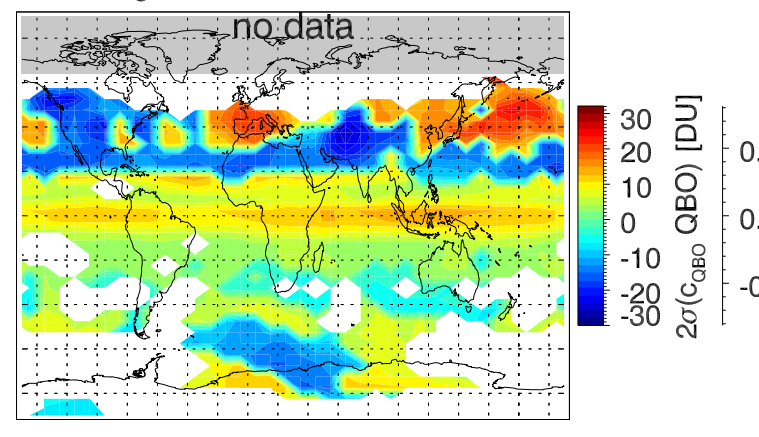

\section{$\mathrm{O}_{3} \mathrm{QBO}$ JJA (SQT)}

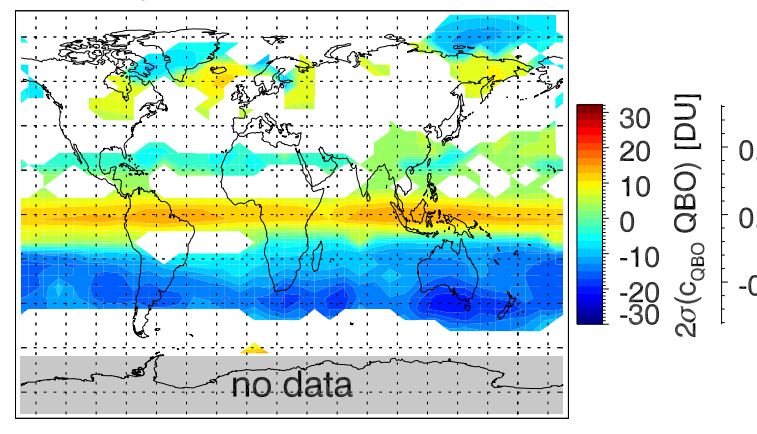

T50 QBO DJF (SQT)

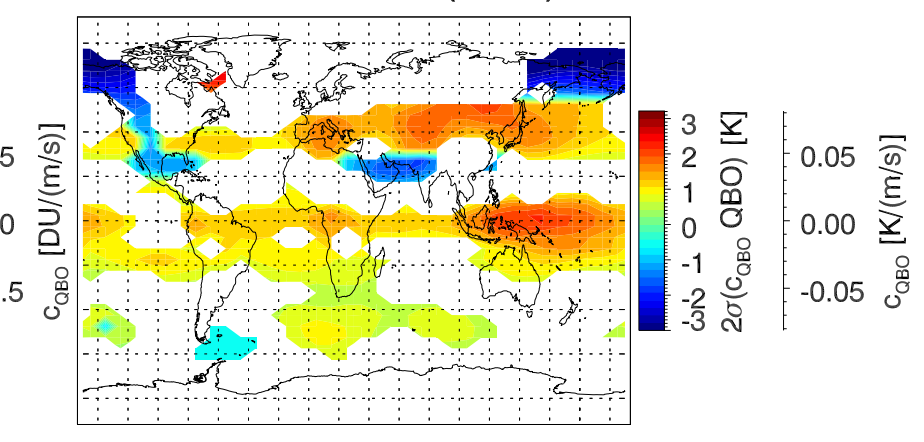

T50 QBO JJA (SQT)

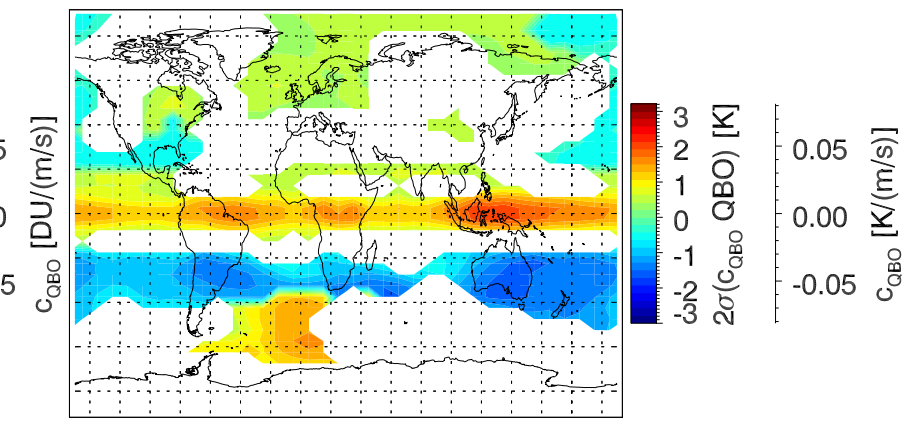

Fig. 5. Same as Fig. 4, but for regression with a reduced set of explanatory variables, containing only QBO, solar cycle and a linear trend.

hand in hand with a weaker meridional circulation, which means lower temperature and low total ozone inside the polar vortex and higher temperature and high total ozone at mid-latitudes. All these features of the Holton-Tan relation between polar vortex strength and the QBO can be seen in Fig. 5. However, the Holton-Tan relation is true in a statistical sense only. It does not hold for every winter. As pointed out by Labitzke and van Loon (2000) the Holton-Tan relation seems to be valid mainly for minima of the 11-year solar cycle. The reverse, i.e. warm polar temperatures for QBOwesterlies, seems to occur during solar maxima. The QBO is therefore only a weak predictor for polar vortex strength. The full regression correctly attributes the high-latitude anomalies to the more direct predictor polar vortex strength (zonal wind at $60^{\circ}$ ), not to the QBO.

An interesting feature of Fig. 4 is the zonally asymmetric QBO signal (red and yellow areas) over Northeastern Asia. It can be interpreted as a strengthening or westward extension of the stratospheric Aleutian anti-cyclone correlated with QBO-westerlies at $30 \mathrm{hPa}$. The feature starts in SON (not shown) as an eastward shift to Northern North-America. In DJF the stratospheric Aleutian anti-cyclone has become stronger above Eastern Asia and this anomaly persists into MAM (not shown). A similar, but weaker feature appears over the Southern Atlantic in Southern Hemisphere winter (JJA), where a stratospheric anti-cyclone is usually found south of Australia and New-Zealand. This anti-cyclone also seems to become stronger in its western part, or extending westwards, during QBO-westerlies at $30 \mathrm{hPa}$.

\subsection{Solar cycle variations}

Figure 6 shows regression results for variations attributed to the solar cycle. As usual, total ozone and $50 \mathrm{hPa}$ temperature exhibit very similar features. Generally, total ozone and $50 \mathrm{hPa}$ temperature are higher during solar maxima and lower during solar minima. The differences typically reach 5 to $25 \mathrm{DU}$ or 0.5 to $2.5 \mathrm{~K}$. Interestingly, variations are smaller in the tropics than in the extra-tropics. The largest variation is found in DJF over parts of the Arctic (red area near Greenland), and in SON over parts of the Antarctic (not shown). Note that very similar results are found, when only solar cycle, QBO and linear trend are allowed as explanatory variables in Eq. (1), and the other explanatory variables are not used.

As pointed out by Labitzke and van Loon (2000), or Ruzmaikin and Feynman (2002), atmospheric variations attributed to the 11-year solar cycle differ between westerly and easterly phases of the QBO. To account for this, regression was also done separately for two subsets of the data. One subset contains only data during times of westerly equatorial zonal wind, the other subset only during easterly winds (at $50 \mathrm{hPa}$ ). Because of splitting into two subsets, the QBO explanatory variable must be omitted in Eq. (1). Note that 

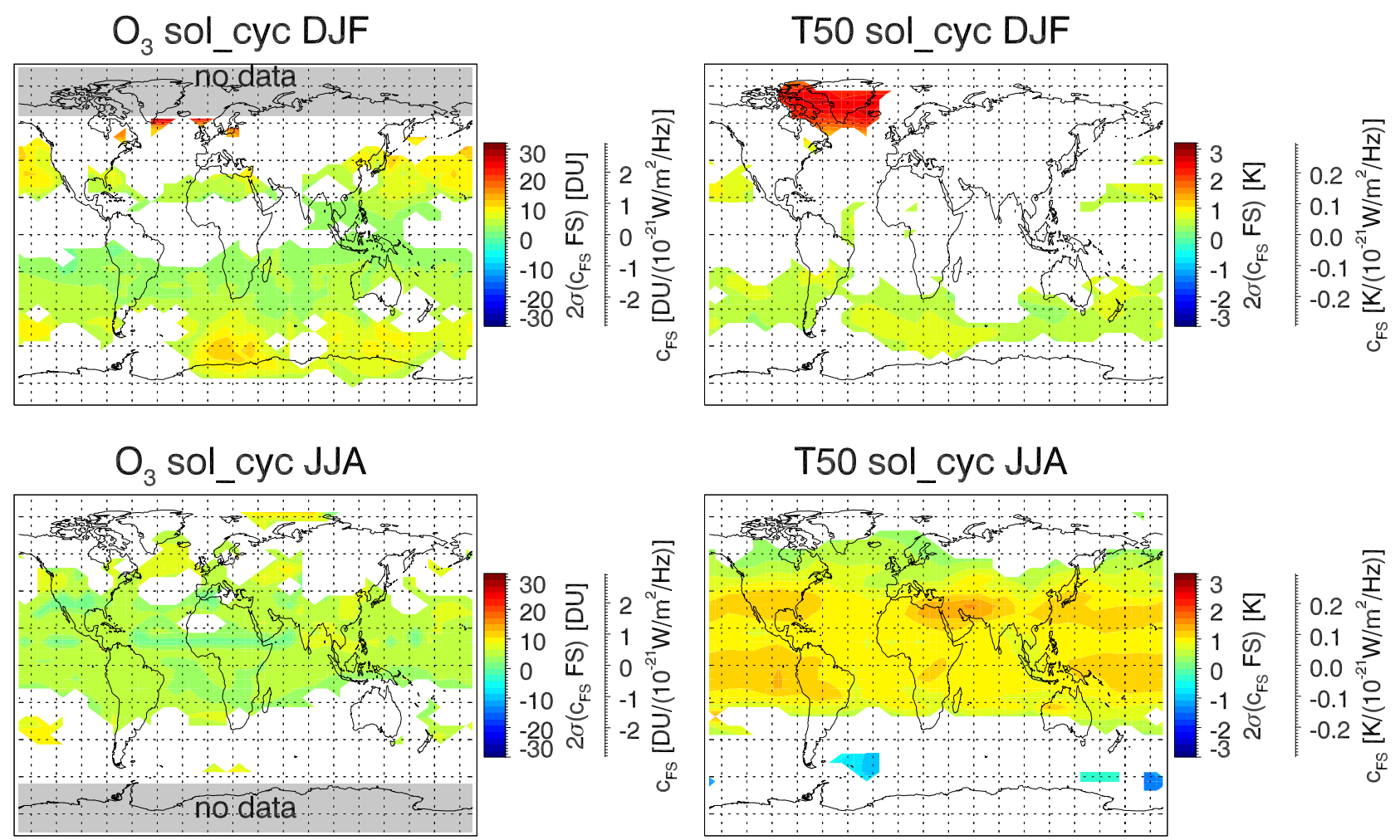

Fig. 6. Same as Fig. 4, but for total ozone fluctuations associated with the 11-year solar cycle. The scales on the false color bars give 2 standard deviations $(2 \sigma)$ of the solar cycle term $c_{F S} F S$ in Eq. (1).The second scales give the size of the solar cycle regression coefficient $c_{F S}$. Yellow and red colors indicate positive correlation between total ozone and solar flux.

following Labitzke and van Loon, $50 \mathrm{hPa}$ winds were used to separate easterly and westerly phases of the QBO, whereas throughout the rest of the paper $30 \mathrm{hPa}$ winds, typically 4 months ahead of $50 \mathrm{hPa}$ winds, are used as the reference. For improved clarity, we also decided to lower the confidence level to $80 \%$, and to show only results for a regression where polar vortex strength, and of course QBO, were not included as explanatory variables. Thus, the results presented here are compatible with most of Labitzke's investigations. Note that results outside of the polar regions change very little, when the full set of explanatory variables, including zonal winds at $60^{\circ} \mathrm{N}$ and $60^{\circ} \mathrm{S}$, is used. Also, results for $50 \mathrm{hPa}$ temperature change very little when the full 1958 to 2001 period is used, instead of the normal 1979 to 2001 period of TOMS/SBUV data.

Figures 7 and 8 show results for the two QBO sub-sets. As might be expected, solar cycle variations found for the complete data-set without grouping (Fig. 6) are similar to the average of the variations found for the two sub-sets (Figs. 7 and 8). However, the solar variation is substantially larger during easterly QBO phases, and is much smaller during westerly phases. At low to mid-latitudes, variations are large and similar in both hemispheres during QBO-East, whereas they are generally weaker, particularly in the winter hemisphere during QBO-West. While SON (not shown) shows a simi- lar picture as DJF, variations during MAM (not shown) are quite different from both DJF and JJA. The MAM variations are quite weak and mostly restricted to high latitudes, during QBO-East, whereas during QBO-West they are strong and similar to, but weaker than, the DJF variations for QBO-East.

From the tropics to mid-latitudes, up to $40^{\circ}$ or $50^{\circ}$, and for both QBO subsets, the solar cycle variations are more or less zonally symmetric. High latitude variations attributed to the solar cycle, however, are not zonal, but localized to certain longitudes. This is similar to the findings for the QBO in Figs. 4 and 5. Where total ozone data are available, they show similar high latitude features as $50 \mathrm{hPa}$ temperature. Between QBO-East and QBO-West, the high latitude variations appear at complementary longitudes: For QBO-West and DJF, $50 \mathrm{hPa}$ temperatures are higher during solar maxima over Europe, and lower over the Northern Pacific (red and blue regions in Fig. 8). For QBO-East and DJF, $50 \mathrm{hPa}$ temperatures are lower during solar maxima over parts of Northern Russia and higher in the North Pacific Region (blue and red areas in Fig. 7). A complementary picture is also seen for JJA in the Southern Hemisphere. There, $50 \mathrm{hPa}$ temperatures are higher during solar maxima in a region south of South America during QBO-East, but are lower during solar maxima over the Southern Pacific during QBO-West. 


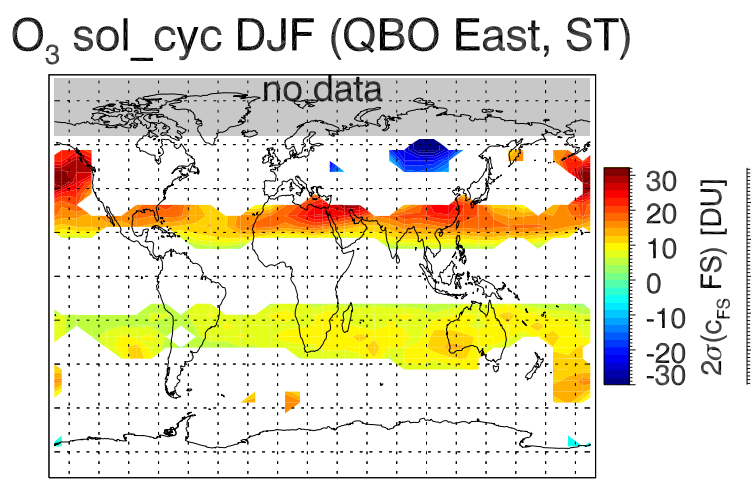

$\mathrm{O}_{3}$ sol_cyc JJA (QBO East, ST)

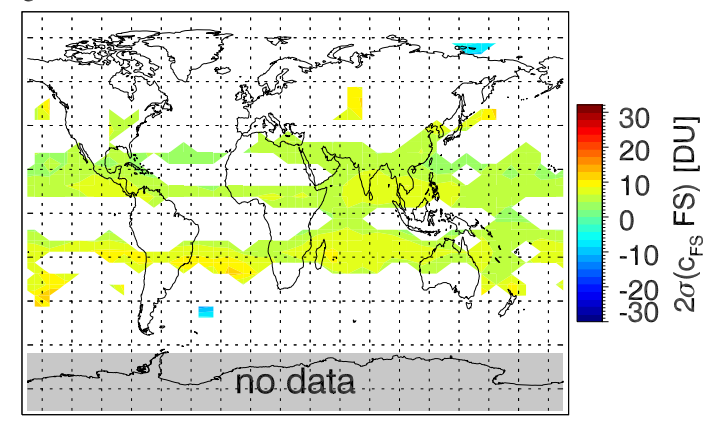

\section{T50 sol_cyc DJF (QBO East, ST)}

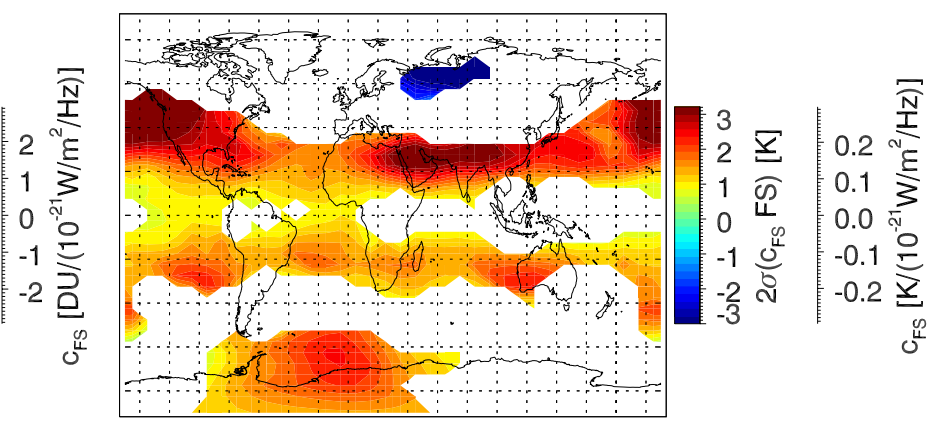

T50 sol_cyc JJA (QBO East, ST)

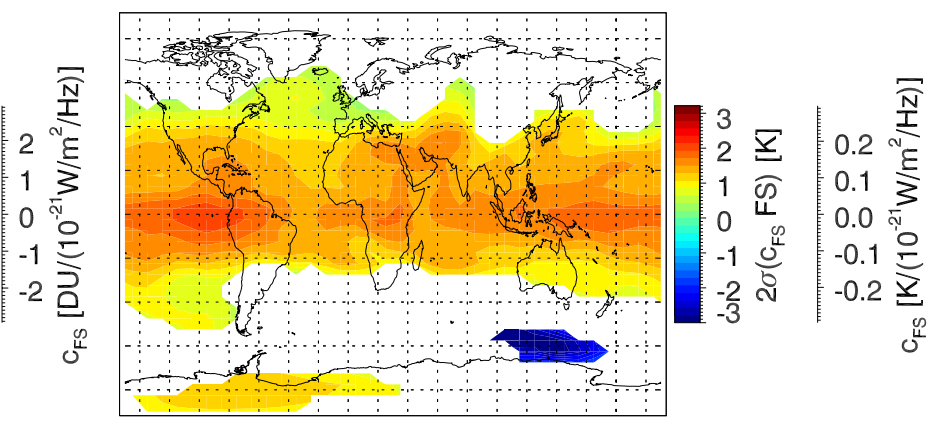

Fig. 7. Same as Fig. 6, but only data during the easterly phase of the QBO (at $50 \mathrm{hPa}$ ) are used. To improve clarity for this figure, as well as for Fig. 8, the confidence level was reduced to $80 \%$, and zonal winds at $60^{\circ} \mathrm{N}$ and $60^{\circ} \mathrm{S}$ were not included as explanatory variables.

These results for total ozone and $50 \mathrm{hPa}$ temperature are broadly consistent with previous results for stratospheric temperatures or total ozone (Zerefos et al., 1997; Hood, 1997; Labitzke and van Loon, 2000). In particular it is confirmed that variations related to the solar cycle differ from season to season and differ between westerly and easterly phases of the QBO (Labitzke and van Loon, 2000; Ruzmaikin and Feynman, 2002). As pointed out by Lee and Smith (2003), regression on data spanning only a few solar cycles probably cannot separate QBO and solar cycle effects completely. Conceptual models indicate that QBO and solar cycle can interact with atmospheric noise to change the probability for warm or cold stratospheric winters (Lawrence et al., 2000). According to Hood (1997), observed changes in lower stratospheric dynamics can explain the total ozone fluctuations and their similarity to the temperature fluctuations. However, general circulation models even including a representation of atmospheric chemistry, largely have not been able to reproduce the full size of the variations observed in the lower stratosphere (Labitzke et al., 2002; Tourpali et al., 2003), particularly at higher latitudes. A deeper understanding of the underlying physical mechanisms is still lacking.

\subsection{Stratospheric aerosol variations}

Since the beginning of regular stratospheric weather records, three major volcanic eruptions, Mt. Pinatubo in 1991, El Chichón in 1982, and Agung in 1963, have resulted in large increases of stratospheric aerosol. Most of the volcanic aerosol leaves the stratosphere through sedimentation within about 2 to 3 years. Light absorption and scattering by the additional particles tends to warm the lower latitude stratosphere. Particularly at cold temperatures and higher latitudes, the particles also provide surface area for chemical reactions, which result in enhanced ozone destruction by chlorine. This was most pronounced for the Pinatubo episode, when stratospheric chlorine loading was higher than at the time of the other eruptions (Solomon, 1999; Robock, 2000).

Based on the 1979 to 1995 total ozone record, Solomon et al. (1996) and McCormack et al. (1997) pointed out that it may be difficult to separate between effects of the 11-year solar cycle and effects from volcanic aerosol, since both major volcanic eruptions of El Chichón in 1982 and Pinatubo in 1991 occurred near solar maximum. Extension of the data record to 2001, almost to the next solar maximum and without another volcanic eruption, seems to have alleviated this problem. In the present study, nearly the same results are obtained for stratospheric aerosol related variations of total ozone and $50 \mathrm{hPa}$ temperature, whether the solar-cycle is 


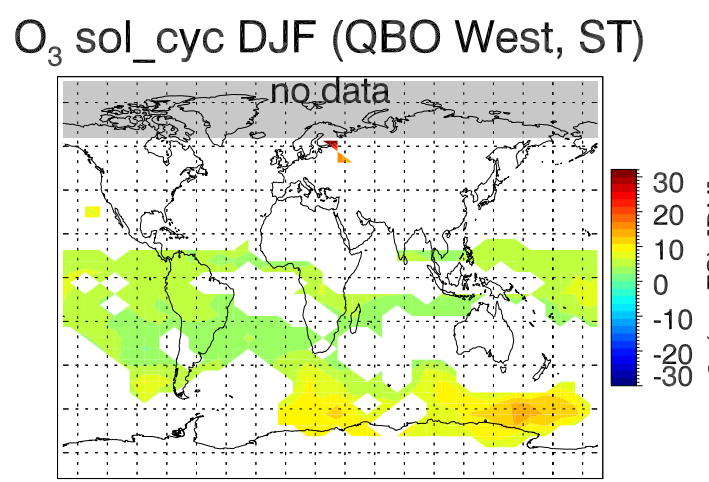

$\mathrm{O}_{3}$ sol_cyc JJA (QBO West, ST)

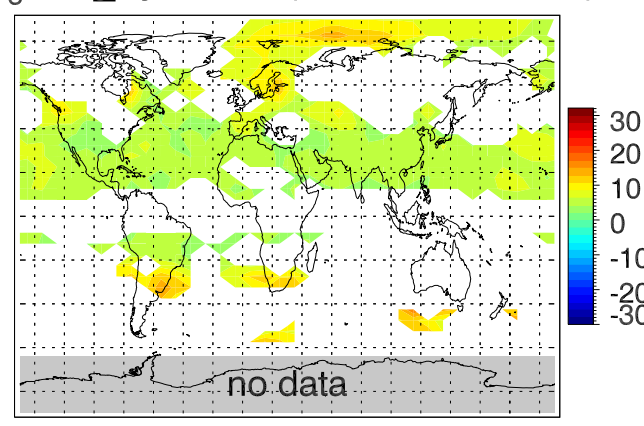

\section{T50 sol_cyc DJF (QBO West, ST)}

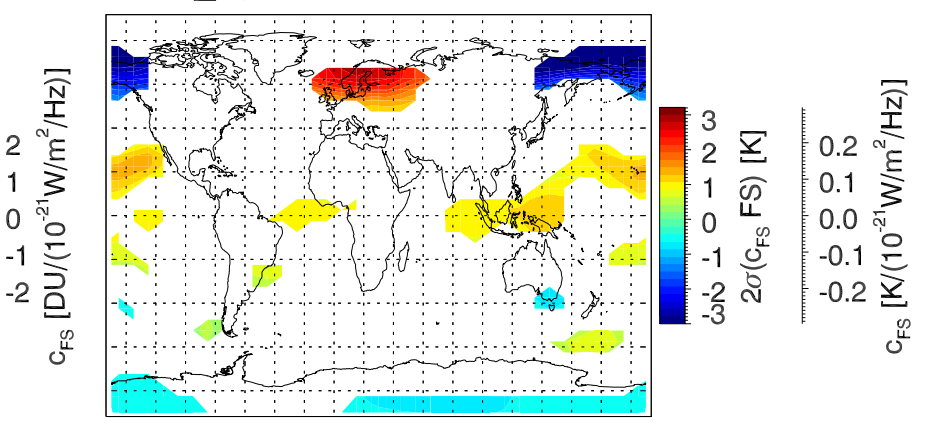

T50 sol_cyc JJA (QBO West, ST)

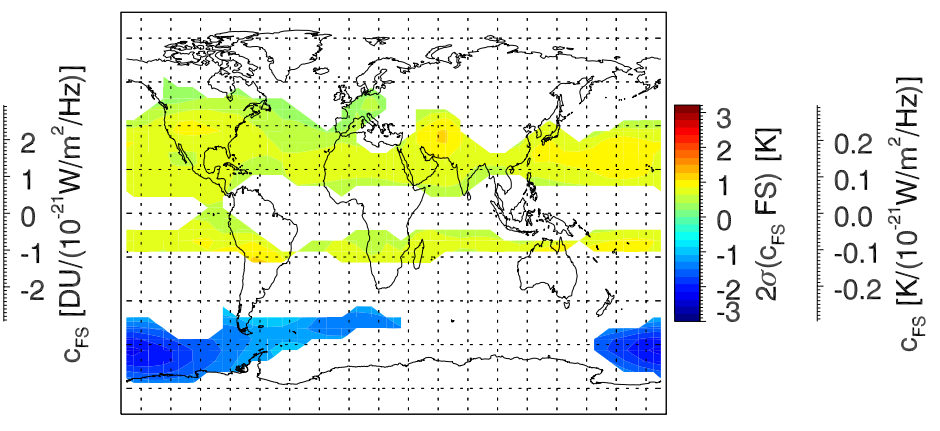

Fig. 8. Same as Fig. 7, but for the westerly phase of the QBO (at $50 \mathrm{hPa}$ ). To improve clarity for this figure, as well as for Fig. 7, the confidence level was reduced to $80 \%$, and zonal winds at $60^{\circ} \mathrm{N}$ and $60^{\circ} \mathrm{S}$ were not included as explanatory variables.

included in the regression or not. Similarly, results for the stratospheric solar-cycle predictor do not depend much on whether the aerosol term is included or not. Also, $50 \mathrm{hPa}$ temperature variations attributed to the stratospheric aerosol term or the solar cycle term change very little when the much longer 1958 to 2001 data-set is used.

The maximum ozone and $50 \mathrm{hPa}$ temperature changes attributed to stratospheric aerosol loading are shown in Fig. 9 for northern spring (MAM) and fall (SON). Since the Mt. Pinatubo eruption resulted in the highest stratospheric aerosol loading for over 50 years, the values in Fig. 9 largely reflect anomalies from the years 1991 to 1993. Different from most other explanatory variables, there is little geographical correlation between the aerosol responses for total ozone and $50 \mathrm{hPa}$ temperature. Temperatures at $50 \mathrm{hPa}$ responded by an increase, typically by 2 to over $3 \mathrm{~K}$, in a broad belt between $40^{\circ} \mathrm{S}$ and $40^{\circ} \mathrm{N}$. The response is very similar for all seasons. At higher latitudes, red areas in Fig. 9 above North America and south-east of Australia in SON give indications for strengthening and/or eastward movement of the Aleutian and Australian stratospheric anti-cyclones. Similar high-latitude features are also seen in winter in the respective hemispheres (DJF and JJA, both not shown). There is no indication of a significant negative temperature response at mid-latitudes.
In contrast to $50 \mathrm{hPa}$ temperature, the ozone response is usually negative. It is largest at high latitudes, smallest in the tropics. Ozone decreases exceeding $40 \mathrm{DU}$ are found at northern mid to high latitudes in spring (MAM) and over parts of Antarctica in southern spring (SON). The ozone response for DJF (not shown) is very similar to MAM. In JJA (not shown) losses are found at lower latitudes like in SON, and the large northern high-latitude losses from MAM remain, but are substantially reduced.

The aerosol responses found here, a $50 \mathrm{hPa}$ temperature increase by up to $3 \mathrm{~K}$ at low latitudes, and total ozone depletions by up to $40 \mathrm{DU}$, mostly at northern high-latitudes, are consistent with previous studies (Angell , 1997; McCormack et al., 1997; Robock, 2000).

\subsection{Zonal wind anomalies at $60^{\circ} \mathrm{N}$ and $60^{\circ} \mathrm{S}, 50 \mathrm{hPa}$}

The intensity of the meridional residual Brewer-Dobson circulation in the winter stratosphere is highly correlated with the strength of the polar winter vortex (Staehelin et al., 2001; Salby and Callaghan, 2002). A stable winter vortex is also a prerequisite for large-scale chemical processing on polar stratospheric cloud particles leading to "ozone-hole" conditions (Solomon, 1999). Zonal wind anomalies at $60^{\circ}$ latitude at the $50 \mathrm{hPa}$ level are a good indicator of vortex strength and were added to the set of explanatory variables. The size of 
$\mathrm{O}_{3}$ aerosol MAM

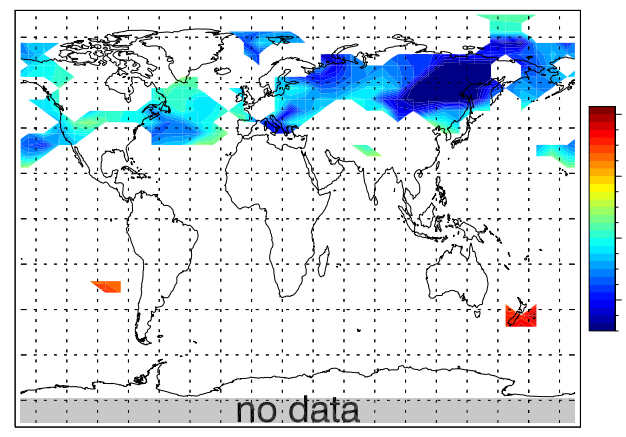

\section{$\mathrm{O}_{3}$ aerosol SON}

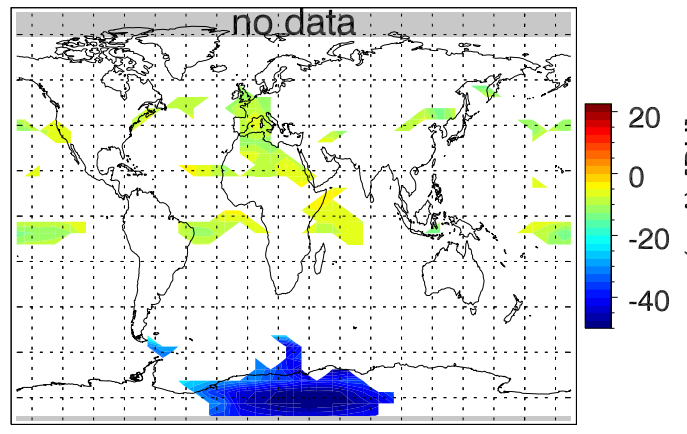

T50 aerosol MAM

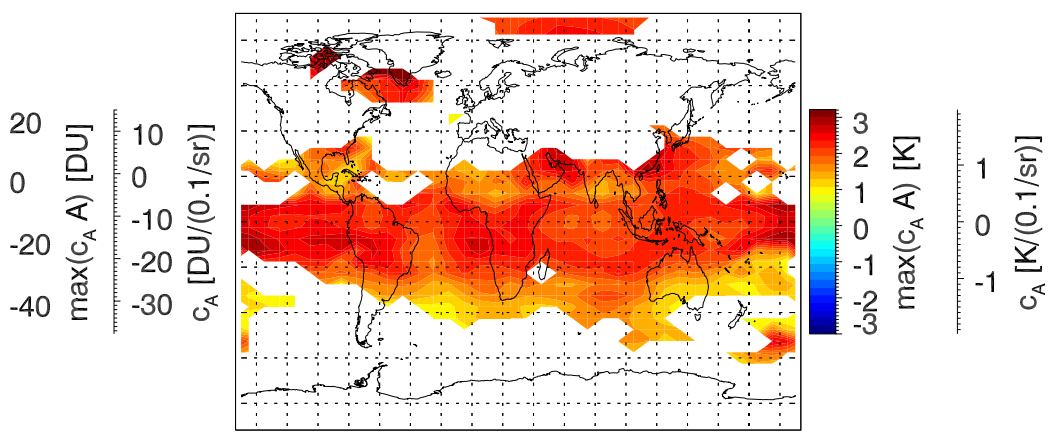

T50 aerosol SON

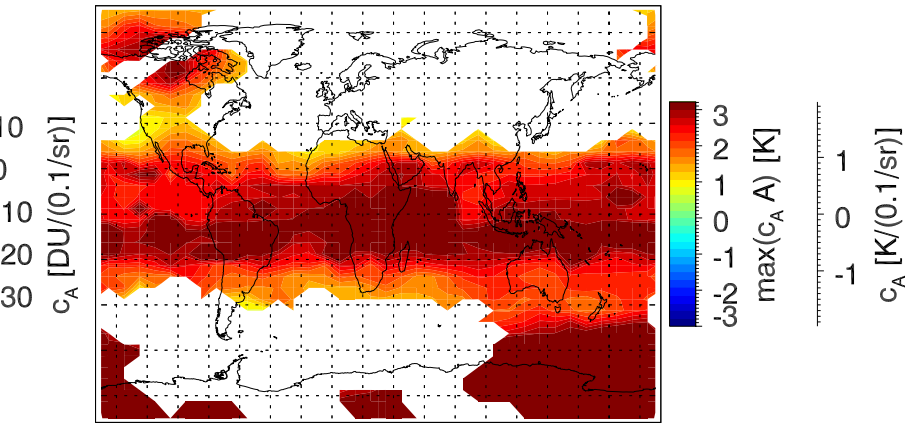

Fig. 9. Same as previous figures, but showing ozone and $50 \mathrm{hPa}$ temperature changes attributed to stratospheric aerosol from the El Chichón and Pinatubo eruption. Here the maximum positive or negative deviation of $c_{A} A$ is shown, not two standard deviations as in the other plots. Note also, that the scale for $c_{A}$ on the right is only approximate, because the aerosol data $A$ vary with latitude.

total ozone and $50 \mathrm{hPa}$ temperature fluctuations attributed to zonal wind anomalies is shown in Figs. 10 and 11 for northern and southern spring.

For high winds and a strong polar vortex, total ozone and temperatures are low in the polar region. The polar variations are very large and reach up to $50 \mathrm{DU}$ or $5 \mathrm{~K}$. Polar total ozone and $50 \mathrm{hPa}$ temperature are inversely correlated to zonal wind. An opposite variation is found at mid- to low latitudes. The temperature variation is larger and is found at higher latitudes than for total ozone. Temperature variations peak at up to $2.5 \mathrm{~K}$ around $30^{\circ}$ to $40^{\circ}$. Total ozone variations are more restricted to the tropics and reach up to $5 \mathrm{DU}$. The Southern Hemisphere variations (SON) are slightly weaker, but more spread out, than in the Northern Hemisphere. Results for northern fall and winter (SON and DJF, both not shown) are very similar to northern spring (MAM). However, variations attributed to southern vortex strength in southern fall and winter (MAM and JJA, both not shown), are much less pronounced than in southern spring (SON). This reflects the much stronger and less variable Antarctic vortex and the generally weaker Brewer-Dobson circulation in the Southern Hemisphere during winter.

These variations of total ozone and $50 \mathrm{hPa}$ temperature reflect the close coupling of mean meridional Brewer-Dobson circulation and polar vortex strength. A strong vortex goes hand in hand with a weak meridional circulation. Less ozone and heat are transported polewards. Total ozone and temperatures remain high at lower latitudes and low at higher latitudes. A strong and cold vortex also favors rapid chemical ozone destruction in spring ("ozone hole"), which will result in low total ozone and, through less ozone radiative heating, also lower $50 \mathrm{hPa}$ temperatures. This effect will enhance the transport effect. It is more relevant for the Northern Hemisphere where "ozone hole" conditions only occur in some years, than for the Southern Hemisphere, where a strong and stable vortex is established in almost every year.

\section{$3.7 \quad E N S O$}

The El Niño/Southern-Oscillation phenomenon $(E N S O)$ is a coupled fluctuation of the tropical Pacific Ocean and the atmosphere (e.g. Coghlan, 2002). During the El Niño warmphase, ocean surface temperature in the Eastern Tropical Pacific is 1 to $2 \mathrm{~K}$ above normal, during the La Niña coldphase it is 1 to $2 \mathrm{~K}$ below normal. These changes in sea surface temperature are accompanied by changes in many atmospheric parameters, e.g. tropospheric winds and rainfall patterns. During El Niño, tropical easterlies weaken, dry conditions are found in the Western Pacific (Australia, Indonesia), 


\section{$\mathrm{O}_{3}$ wind $60^{\circ} \mathrm{N}$ MAM}

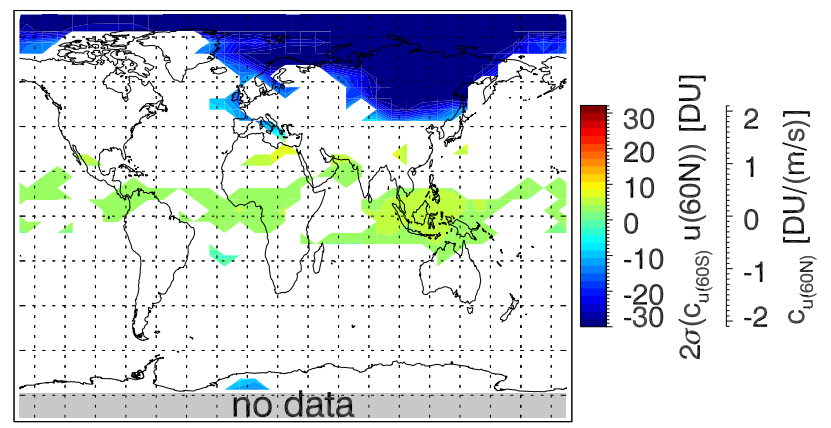

T50 wind_60N MAM

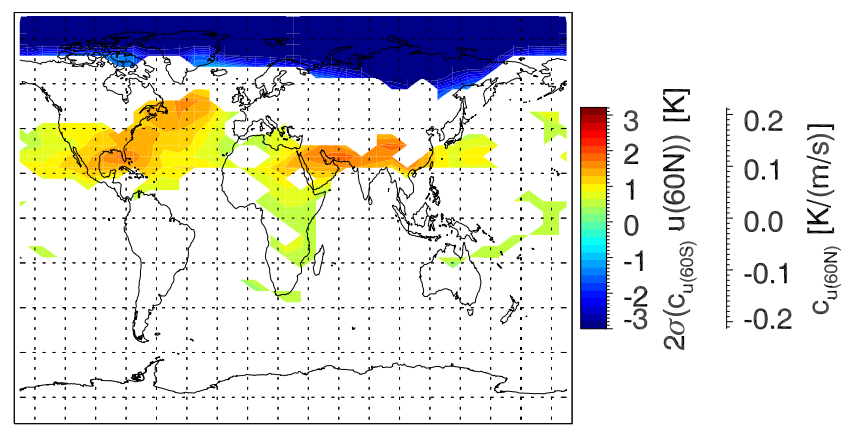

Fig. 10. Same as previous figures, but showing variations related to polar vortex strength, which is represented by zonal wind anomalies at $60^{\circ} \mathrm{N}, 50 \mathrm{hPa}$.

\section{$\mathrm{O}_{3}$ wind_60 6 SON}

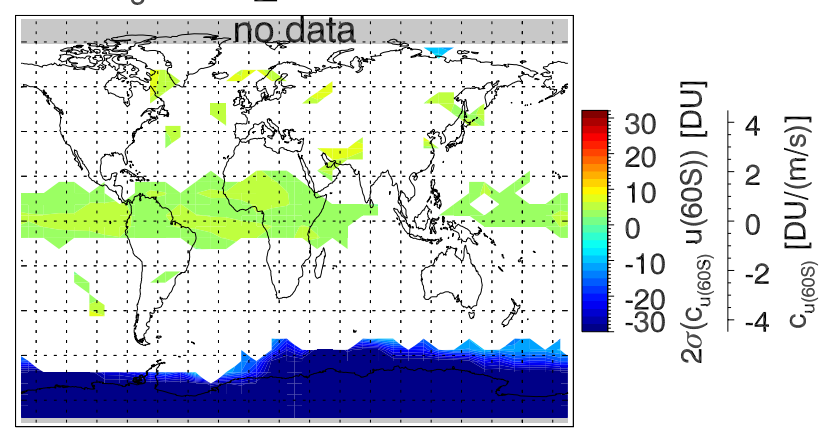

T50 wind $60^{\circ}$ S SON

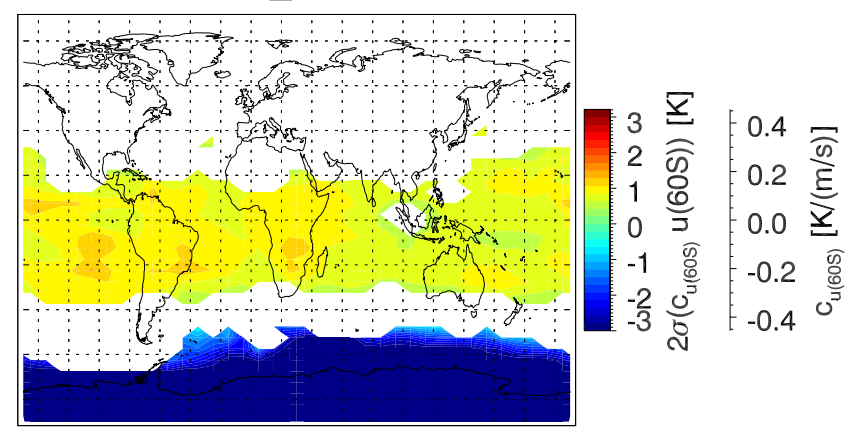

Fig. 11. Same as Fig. 10, but for zonal wind anomalies at $60^{\circ} \mathrm{S}, 50 \mathrm{hPa}$.

wet conditions extend further into the Eastern Pacific (South America). The warmer sea surface temperatures also lead to a warmer troposphere and a higher tropopause throughout most of the tropics, but particularly over the Eastern Tropical Pacific. In the extra tropics, particularly over regions in Eastern Asia and the Pacific, temperatures and tropopause height are lower (Kiladis et al., 2001). The opposite is the case for La Niña. ENSO is accompanied by residual circulation cells with descending and ascending branches in the troposphere. These are compensated by opposing motions in the lower stratosphere (Gettelman et al., 2001; Kiladis et al., 2001). ENSO thus leads to lower stratospheric temperature and total ozone anomalies, that are opposite to the temperature anomalies in the troposphere.

Figure 12 shows the typical size of total ozone and $50 \mathrm{hPa}$ temperature changes found between La Niñas and El Niños for DJF. Note that the ENSO explanatory variable used here (NCEP's Southern Oscillation Index) is positive for La Niña events and negative during El Niños. Thus, Fig. 12 shows that total ozone and $50 \mathrm{hPa}$ temperature are high in DJF during La Niña throughout parts of the tropics, particularly above the Eastern Pacific and the tropical Atlantic for total ozone. In the tropics, the difference between La Niña and El Niño is typically about 5 to $10 \mathrm{DU}$ or 0.5 to $1 \mathrm{~K}$. The differences are largest in DJF and above the Eastern Pacific. SON and MAM (both not shown) exhibit similar, generally weaker and less significant, variations. A similar tropical $E N S O$-related variation, i.e. zonal changes up to $10 \mathrm{DU}$ with a superimposed see-saw between the Eastern and Western Pacific, has been reported, e.g. by Shiotani (1992). Outside of the tropics, total ozone and $50 \mathrm{hPa}$ temperature are generally low during La Niña, and high during El Niño. This is most pronounced in the summer hemisphere (DJF and JJA, the latter is not shown).

A striking, zonally asymmetric, feature are the substantially colder $50 \mathrm{hPa}$ temperatures found during La Niña over Eastern Asia ( $-3 \mathrm{~K}$, blue region in Fig. 12). They seem to be coupled to warmer temperatures over Europe $(+3 \mathrm{~K}$, red region). A positive anomaly over Europe is also found for total ozone. However, the strong temperature anomaly over Eastern Asia does not appear in the total ozone response, or is not significant there. The temperature anomalies indicate a weakening of the westerly part of the Aleutian anti-cyclone. This might be related to a generally stronger and more stable Arctic polar vortex during La Niña (Labitzke and van Loon, 1999). As before for QBO and solar cycle, a strong polar signal from ENSO is likely taken over by the zonal wind at $60^{\circ}$ explanatory variable. 
$\mathrm{O}_{3}$ ENSO DJF
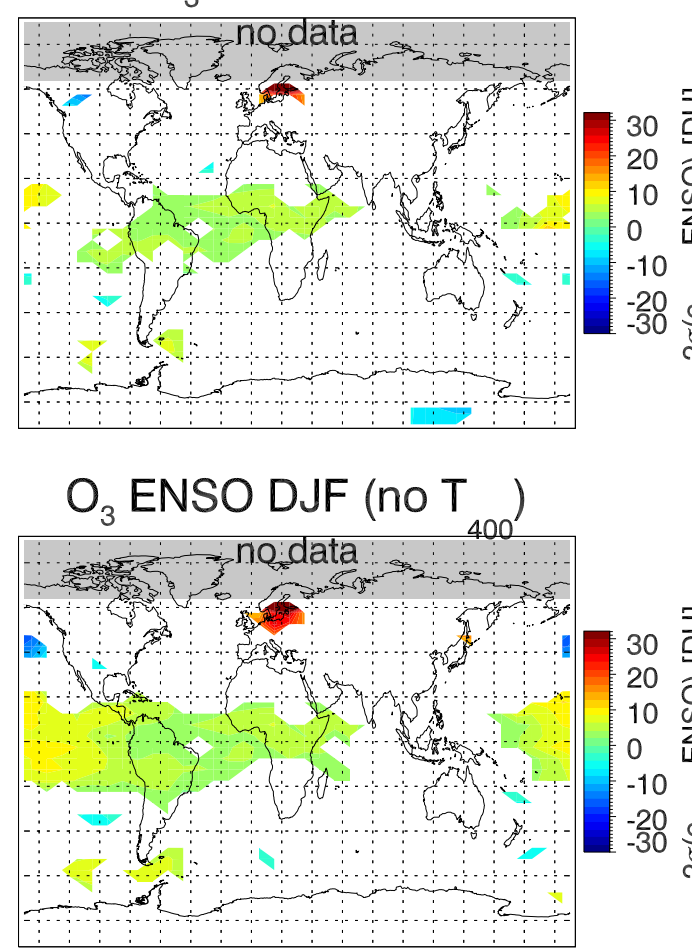

T50 ENSO DJF
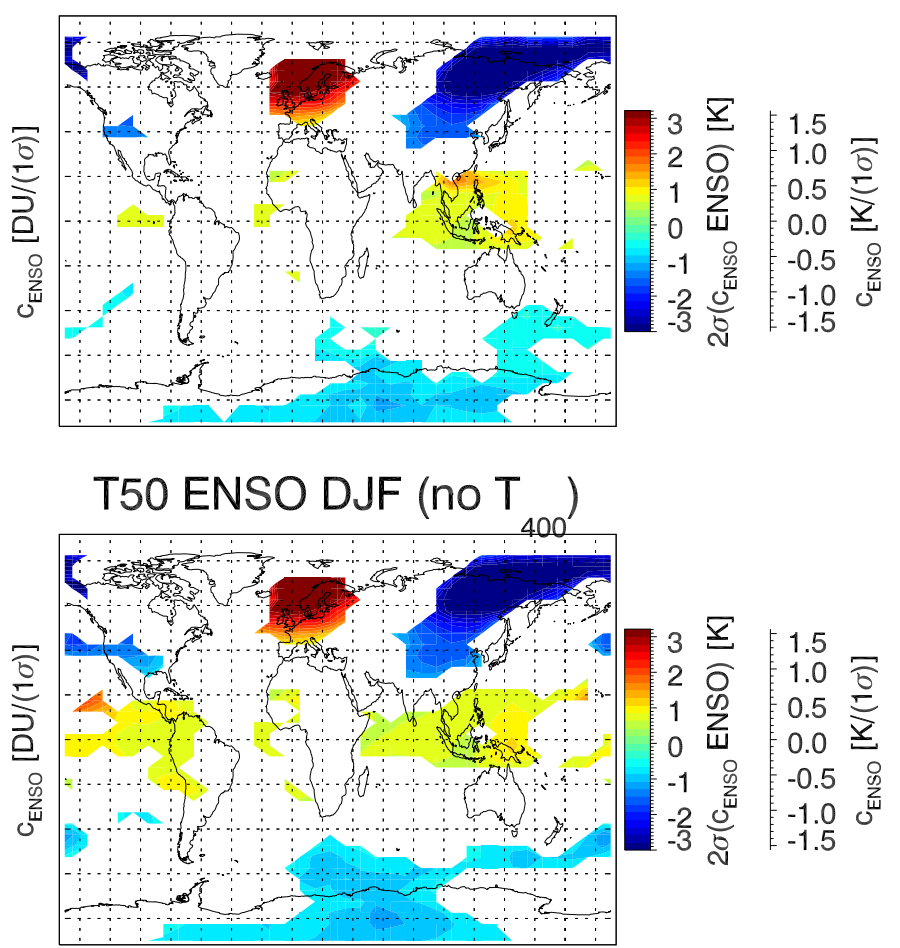

Fig. 12. Same as previous figures, but showing the influence of El Niño/Southern-Oscillation on total ozone and $50 \mathrm{hPa}$ temperature. Top panels: Obtained with full set of explanatory variables, including $400 \mathrm{hPa}$ temperature. Bottom panels: Reduced set of explanatory variables, without $400 \mathrm{hPa}$ temperature.

As mentioned, tropospheric temperature, e.g. at $400 \mathrm{hPa}$, and El Niño are highly correlated in the tropics and some other regions. When both $400 \mathrm{hPa}$ temperature and an El Niño explanatory variable are used in the regression, one, the other, or both may take over part of the variation. To give an indication how serious this dependence might be, Fig. 12 contrasts ENSO results for the full regression according to Eq. (1) in the upper panels, with results where $T$ (400) was not included as an explanatory variable in the lower panels. Differences between the two sets of explanatory variables are generally small and occur mainly in the tropics. When $400 \mathrm{hPa}$ temperature is included (upper panels), total ozone and temperature variations attributed to the $E N S O$ predictor are weaker in the tropics, particularly over the Eastern Pacific, ENSO's main center of action. In this region, $400 \mathrm{hPa}$ temperature takes over part of the variations that otherwise would be attributed to the ENSO explanatory variable. Similar but smaller changes are found for the other seasons (not shown). Although T(400) and ENSO are an example of highly correlated explanatory variables, the results do not depend very much on whether the other explanatory variable is included or not. For other explanatory variables the effects are usually even smaller.

\section{Conclusions}

Multiple linear regression analysis provides a good near global picture of natural and anthropogenic contributions to interannual variations of total ozone and lower stratospheric temperature, e.g. at $50 \mathrm{hPa}$. For most explanatory variables the geographical distribution of the attributed total ozone and $50 \mathrm{hPa}$ temperature variations is very similar. It appears that interannual fluctuations of both parameters are controlled to a large degree by the same physical processes. As a rule of thumb, a $10 \mathrm{DU}$ change in total ozone corresponds to a $1 \mathrm{~K}$ change of $50 \mathrm{hPa}$ temperature. The length of the 1979 to $2001 \mathrm{TOMS} / \mathrm{SBUV}$ data record makes it possible to get a fairly good separation of different contributors. Note that results for $50 \mathrm{hPa}$ temperature change very little when the even longer 1958 to 2001 time period is used. There may still be difficulties, e.g. separating solar cycle and QBO related variations, or variations related to both $\mathrm{QBO}$ and ENSO (Lee and Smith, 2003). However, our sensitivity tests indicate no major problems. Although new data have been added and the picture presented here has become more comprehensive, findings are not fundamentally different from earlier studies, where the various contributions were studied separately (Shiotani, 1992; McCormack et al., 1997; Zerefos et al., 1997; Labitzke and van Loon, 2000; Baldwin et al., 2001). 
Table 1. Typical size of total ozone and $50 \mathrm{hPa}$ temperature variations attributed to different explanatory variables $X$ by linear regression of Eq. (1). The second and third columns give 2 standard deviations $(2 \sigma)$ of the respective terms $c_{X} X$, except for stratospheric aerosol $A$, where the maximum ozone and temperature change (after the Pinatubo eruption) are given. The fourth and fifth column give the typical size of the regression coefficients $c_{X}$

\begin{tabular}{|c|c|c|c|c|}
\hline \multirow[t]{2}{*}{$X$} & \multicolumn{2}{|c|}{$2 \sigma\left(c_{X} X\right)$} & \multicolumn{2}{|c|}{$c_{X}$} \\
\hline & ozone & $50 \mathrm{hPa}$ temperature & ozone & $50 \mathrm{hPa}$ temperature \\
\hline$T R$ & & & -5 to $-30 \mathrm{DU} /$ decade & -0.5 to $-1.5 \mathrm{~K} /$ decade \\
\hline$T(400)$ & 5 to $30 D U$ & 0.5 to $3 K$ & -3 to $-12 D U / K$ & -0.3 to $-1 K / K$ \\
\hline$Q B O(10 / 30)$ & 5 to $25 D U$ & 0.5 to $2.5 K$ & -0.5 to $+0.7 \mathrm{DU} /(\mathrm{m} / \mathrm{s})$ & -0.05 to $+0.07 \mathrm{~K} /(\mathrm{m} / \mathrm{s})$ \\
\hline$F S$ & 5 to $25 D U$ & 0.5 to $2.5 \mathrm{~K}$ & 0.3 to $1.5 \frac{10^{21} \mathrm{DU}}{\mathrm{W} /\left(\mathrm{m}^{2} \mathrm{~Hz}\right)}$ & 0.03 to $0.15 \frac{10^{21} \mathrm{~K}}{\mathrm{~W} /\left(\mathrm{m}^{2} \mathrm{~Hz}\right)}$ \\
\hline$A$ & up to $-40 \mathrm{DU}$ & up to $+3 K$ & -100 to $-350 D U /(1 / s r)$ & 15 to $20 K /(1 / s r)$ \\
\hline$u(60 N)$ & 5 to $50 \mathrm{DU}$ & 0.5 to $5 K$ & +0.3 to $-3 \mathrm{DU} /(\mathrm{m} / \mathrm{s})$ & +0.05 to $-0.3 \mathrm{~K} /(\mathrm{m} / \mathrm{s})$ \\
\hline$u(60 S)$ & 5 to $40 D U$ & 0.5 to $4 K$ & +0.4 to $-5 \mathrm{DU} /(\mathrm{m} / \mathrm{s})$ & +0.1 to $-0.5 \mathrm{~K} /(\mathrm{m} / \mathrm{s})$ \\
\hline ENSO & 5 to $10 D U$ & 0.5 to $1 K$ & 2 to $5 \mathrm{DU}$ & 0.25 to $0.5 K$ \\
\hline
\end{tabular}

For the different explanatory variables, ozone and temperature fluctuations range from about $5 \mathrm{DU}$ or $0.5 \mathrm{~K}$ (two standard deviations of the corresponding time series term in Eq. (1)) to $50 \mathrm{DU}$ or $5 \mathrm{~K}$, respectively. A summary is given in Table 1. Large variations come from the linear trend term, up to $-30 \mathrm{DU}$ or $-1.5 \mathrm{~K} / \mathrm{dec}$ de, from terms related to polar vortex strength, up to $50 \mathrm{DU}$ or $5 \mathrm{~K}$, from tropospheric meteorology, up to $30 \mathrm{DU}$ or $3 \mathrm{~K}$, or from the QBO, up to $25 \mathrm{DU}$ or $2.5 \mathrm{~K}$. The 11-year solar cycle, up to $25 \mathrm{DU}$ or $2.5 \mathrm{~K}$, or ENSO, up to $10 \mathrm{DU}$ or $1 \mathrm{~K}$, are somewhat smaller contributors. A large but sporadic variation comes from stratospheric aerosol, which leads to warming up to $3 \mathrm{~K}$ at low latitudes and ozone depletion up to $40 \mathrm{DU}$ at high latitudes. Variations related to QBO, polar vortex strength, and to a lesser degree, to ENSO exhibit a clear inverse correlation between low latitudes and higher latitudes. Variations related to solar cycle or $400 \mathrm{hPa}$ temperature, however, have the same sign over most of the globe.

For most explanatory variables, total ozone and $50 \mathrm{hPa}$ temperature variations are zonally symmetric at low and midlatitudes. At high latitudes, however, zonal symmetry is more the exception than the rule. For example, QBO, solar-cycle or ENSO, all related to polar vortex strength and stratospheric warmings (Labitzke and van Loon, 1999), seem to influence position and strength of the stratospheric anti-cyclones over the Aleutians and south of Australia. This indicates that latitudinal effects need to be considered, when trying to understand the physical mechanisms leading to the observed connections at higher latitudes (see also Callaghan and Salby, 2002). Two-dimensional models cannot resolve latitudinal structures, and this may be a major drawback. Recently, several three-dimensional global circulation models include a representation of stratospheric chemistry with feedback of the chemical species on radiative heating and cooling (Austin et al., 2003). Two such models, MA-ECHAM and ECHAMDLR, are currently used for transient simulations. These simulations account for source gas changes over the last 40 years, for solar-flux changes, for changing sea-surface temperatures, QBO and volcanic aerosol. It is planned to analyze these simulations in the same fashion as has been done for the observations in this paper. Comparison between simulated and observed variations should help towards a much better understanding of the underlying mechanisms.

Acknowledgements. This investigation is part of the KODYACS project, funded under AF02000 (www.afo2000.de) by the German Ministry for Education and Research, grant ATF43. Comments and helpful suggestions by Dr. Lon Hood and anonymous reviewers are gratefully acknowledged.

\section{References}

Andrews, D. G., Holton, J. R., and Leovy, C. B.: Middle Atmosphere Dynamics, Academic Press, San Diego, USA, 481, 1987.

Angell, J. K.: Stratospheric warming due to Agung, El Chichón, and Pinatubo taking into account the Quasi-Biennial Oscillation, J. Geophys. Res., 102, 9479-9485, 1997.

Appenzeller, C., Weiss, A. K., and Stähelin, J.: North Atlantic Oscillation modulates total ozone winter trends, Geophys. Res. Lett., 27, 1134-1138, 2000.

Austin, J. A., Shindell, D., Beagley, S. R., Brühl, C., Dameris, M., Manzini, E., Nagashima, T., Newman, P., Pawson, S., Pitari, G., Rozanov, E., Schnadt, C., and Shepherd, T. G.: Uncertainties and assessments of chemistry-climate models of the stratosphere, Atm. Chem. Phys., 3, 1-27, 2003.

Baldwin, M. P. and Dunkerton, T. J.: Propagation of the Arctic Oscillation from the stratosphere to the troposphere, J. Geophys. Res., 104, 30 937-30 946, 1999.

Baldwin, M. P., Gray, L. J., Dunkerton, T. J., Hamilton, K., Haynes, P. H., Randel, W. J., Holton, J. R., Alexander, M. J., Hirota, I., Horinouchi, T., Jones, D. B. A., Kinnersley, J. S., Marquardt, C., and Takahashi, M.: The Quasi-Biennial Oscillation, Rev. Geophys., 39, 179-229, 2001.

Bodeker, G. E., Scott, J. C., Kreher, K., and McKenzie, R. L.: Global ozone trends in potential vorticity coordinates using 
TOMS and GOME intercompared against the Dobson network: 1978-1998, J. Geophys. Res., 106, 23 029-23 042, 2001.

Bojkov, R. D., Bishop, L., Hill, W. J., Reinsel, G. C., and Tiao, G. C.: A statistical trend analysis of revised Dobson Total Ozone data over the Northern hemisphere, J. Geophys. Res., 95, 97859807, 1990.

Bojkov, R. D. and Fioletov, V. E.: Estimating the global ozone characteristics during the last 30 years, J. Geophys. Res., 100, 16 537-16 551, 1995.

Callaghan, P. F. and Salby, M. L.: Three-Dimensionality and forcing of the Brewer-Dobson circulation, J. Atmos. Sci., 59, 976991, 2002.

Coughlan, C.: El Niño - causes, consequences and solutions, Weather, 57, 209-215, 2002.

Draper, N. R. and Smith, H.: Applied Regression Analysis, WileyInterscience, New York, 706, 1998.

Engel, A., Schmidt, U., and McKenna, D.: Stratospheric trends of CFC-12 over the past two decades: recent observational evidence of declining growth rates, Geophys. Res. Lett., 25, 3319-3322, 1998.

Fioletev, V. E., Bodeker, G. E., Miller, A. J., McPeters, R. D., and Stolarski, R.: Global and zonal total ozone variations estimated from ground-based and satellite measurements: 1964-2000, J. Geophys. Res., 107, 4647, doi:10.1029/2001JD001350, 2002.

Gettelman, A., Randel, W. J., Massie, S., Wu, F., Read, W. G., and Russell III, J. M.: El Niño as a natural experiment for studying the Tropical Tropopause Region, J. Clim., 14, 3375-3392, 2001.

Harris, J. M., Oltmans, S. J., Bodeker, G. E., Stolarski, R., Evans, R. D., and Quincy, D. M.: Long-term variations in total ozone derived from Dobson and satellite data, Atmosph. Environ., 37, 3167-3175, 2003.

Holton, J. R. and Tan, H.-C.: The influence of the equatorial quasibiennial oscillation on the global circulation at $50 \mathrm{mb}$, J. Atmos. Sci., 37, 2200-2208, 1980.

Hood, L. L.: The solar cycle variation of total ozone: Dynamical forcing in the lower stratosphere, J. Geophys. Res., 102, 13551370, 1997.

Hood, L. L., Rossi, S., and Beulen, M.: Trends in lower stratospheric zonal winds, Rossby wave breaking behavior, and column ozone at northern mid latitudes, J. Geophys. Res., 104, 24 321-24339, 1999.

Jäger, H., Uchino, O., and Nagai, T.: Ground-based remote sensing of the decay of the Pinatubo eruption cloud at three Northern Hemisphere sites, Geophys. Res. Lett., 22, 607-610, 1995.

Kiladis, G. B., Straub, K. H., Reid, G. C., and Gage, K. S.: Aspects of interannual and intra seasonal variability of the tropopause and lower stratosphere, Q. J. Roy. Met. Soc., 127, 1961-1983, 2001.

Kistler, R., Kalnay, E., Collins, W., Saha, S., White, G., Woollen, J., Chelliah, M., Ebisuzaki, W., Kanamitsu, M., Kousky, V., van den Dool, H., Jenne, R., and Fiorino, M.: The NCEP-NCAR 50Year Reanalysis: Monthly Means, CD-ROM and Documentation, Bull. Am. Met. Soc., 82, 247-267, http://wesley.wwb.noaa. gov/reanalysis.html, 2001.

Koch, G., Wernli, H., Staehelin, J., and Peter, T.: A Lagrangian analysis of stratospheric ozone variability and long-term trends above Payerne (Switzerland) during 1970-2001, J. Geophys. Res., 107, 4373, doi:10.1029/2001JD001550, 2002.

Labitzke, K. and van Loon, H.: The stratosphere: phenomena, history, and relevance, Springer Verlag, Berlin, 197, 1999.
Labitzke, K. and van Loon, H.: The QBO effect on the solar signal in the global stratosphere in the winter of the Northern Hemisphere, J. Atmos. Solar-Terr. Phys., 62, 621-628, 2000.

Labitzke, K., Austin, J., Butchart, N., Knight, J., Takahashi, M., Nakamoto, M., Nagashima, T., Haigh, J., and Williams, V.: The global signal of the 11-year solar cycle in the stratosphere: observations and models, J. Atmos. Solar-Terr. Phys., 64, 203-210, 2002.

Lawrence, J. K., Cavidad, A. C., and Ruzmaikin, A.: The response of atmospheric circulation to weak solar forcing J. Geophys. Res., 105, 24 839-24 848, 2000.

Lee, H. and Smith, A. K.: Simulation of the combined effects of solar cycle, quasi-biennial oscillation, and volcanic forcing on stratospheric ozone changes in recent decades, J. Geophys. Res., 108, ACH 4, doi:10.1029/2001JD001503, 2003.

McCormack, J. P., Hood, L. L., Nagatani, R., Miller, A. J., Planet, W. G., and McPeters, R. D.: Approximate separation of volcanic and 11-year signals in the SBUV-SBUV/2 total ozone record over the 1979-1995 period, Geophys. Res. Lett., 24, 2729-2732, 1997.

Perlwitz, J. and Graf, H.-F.: The statistical connection between tropospheric and stratospheric circulation of the Northern Hemisphere in winter, J. Clim., 8, 2281-2295, 1995.

Ramaswamy, V., Chanin, M. L., Angell, J., Barnett, J., Gaffen, D., Gelman, M., Keckhut, P., Koshelkov, Y., Labitzke, K., Lin, J. J. R., O`Neil, A., Nash, J., Randel, W., Rood, R., Shiotani, M., Swinbank, R., and Shine, K.: Stratospheric temperature trends: observations and model simulations, Rev. Geophys., 39, 71-122, 2001.

Randel, W. J. and Cobb, J. B.: Coherent variations of monthly mean total ozone and lower stratospheric temperature, J. Geophys. Res., 99, 5433-5447, 1994.

Reed, R. J.: The role of vertical motions in ozone-weather relationship, J. Meteor., 7, 263-267, 1950.

Reid, G. C.: Seasonal and interannual temperature variations in the tropical stratosphere, J. Geophys. Res., 99, 18 923-18 932, 1994.

Robock, A.: Volcanic eruptions and climate, Rev. Geophys., 38, 191-219, 2000.

Ruzmaikin, A. and Feynman, J.: Solar influence on a major mode of atmospheric variability, J. Geophys. Res., 107, ACL 7, doi:10.1029/2001JD001239, 2002.

Sato, M., Hansen, J. E., Lacis, A., and Thomason, L. W.: Stratospheric aerosol optical thickness, http://www.giss.nasa.gov/data/ strataer/, 2003.

Salby, M. L. and Callaghan, P. F.: Fluctuations of total ozone and their relationship to stratospheric air motions, J. Geophys. Res., 98, 2715-2727, 1993.

Salby, M. L. and Callaghan, P. F.: Interannual changes of the stratospheric circulation: relationship to ozone and tropospheric structure, J. Clim., 24, 3673-3685, 2002.

Santer, B. D., Hnilo, J. J., Wigley, M. L., Boyle, J. S., Doutriaux, C., Fiorino, M., Parker, D. E., and Taylor, K. E.: Uncertainties in the observationally based estimates of temperature change in the free atmosphere, J. Geophys. Res., 104, 6305-6333, 1999.

Shiotani, M.: Annual, Quasi-Biennial and El Niño-Southern Oscillation ENSO time-scale variations in Equatorial Total Ozone, J. Geophys. Res., 97, 7625-7633, 1992.

Solomon, S., Portmann, R. W., Garcia, R. R., Thomason, L. W., Poole, L. R., and McCormick, M. P.: The role of aerosol varia- 
tions in anthropogenic ozone depletion at northern midlatitudes, J. Geophys. Res., 101, 6713-6727, 1996.

Solomon, S.: Stratospheric ozone depletion: A review of concepts and history, Rev. Geophys., 37, 275-316, 1999.

SPARC/IOC/GAW: Assessment of Trends in the Vertical Distribution of Ozone, SPARC Report No. 1, WMO Global Ozone Research and Monitoring Project-Report No. 44, 1998, http: //www.aero.jussieu.fr/ $\sim$ sparc/SPARCReport1/.

Staehelin, J., Harris, N. R. P., Appenzeller, C., and Eberhard, J.: Ozone trends: A review, Rev. Geophys., 39, 231-290, 2001.

Steinbrecht, W., Claude, H., Köhler, U., and Hoinka, K. P.: Correlations between tropopause height and total ozone: Implications for long-term changes, J. Geophys. Res., 103, 19 183-19192, 1998.

Steinbrecht, W., Claude, H., Köhler, U., and Winkler, P.: Interannual changes of total ozone and Northern Hemisphere circulation patterns, Geophys. Res. Lett., 28, 1191-1194, 2001.

Stolarski, R. S. and Hollandsworth Frith, S.: Combined total ozone record from TOMS and SBUV instruments, http://code916.gsfc. nasa.gov/Data_services/merged/mod_data.public.html, 2002.

Tourpali, K., Schuurmans, C. J. E., van Dorland, R., Steil, B., and Brühl, C.: Stratospheric and tropospheric response to enhanced solar UV-radiation: A model study, Geophys. Res. Lett., 30, doi: 10.1029/2002GL016650, 2003.
Trenberth, K. E., Stepaniak, D. P., Hurrell, J. W., and Fiorino, M.: Quality of Reanalyses in the tropics, J. Clim., 14, 1499-1510, 2001.

van Loon, H. and Labitzke, K.: The signal of the 11-year solar cycle in the global stratosphere, J. Atmos. Solar-Terr. Phys., 61, 53-61, 1999.

WMO (World Meteorological Organization): Scientific Assessment of Ozone Depletion: 2002, Global Ozone Research and Monitoring ProjectReport No. 47, 498, Geneva, http://www.wmo.ch/ web/arep/ozone.html, 2003.

Yang, H. and Tung, K. K.: On the phase propagation of extra tropical Quasi-Biennial Oscillation in observational data, J. Geophys. Res., 100, 9091-9100, 1995.

Zerefos, C. S., Bais, A. F., Ziomas, I. C., and Bojkov, R. D.: On the relative importance of Quasi-Biennial Oscillation and El Niño Southern Oscillation in the revised Dobson Total Ozone records, J. Geophys. Res., 97, 10 135-10 144, 1992.

Zerefos, C. S., Tourpali, K., Bojkov, B. R., Balis, D. S., Rognerund, B., and Isaksen, I. S. A.: Solar activity-total column ozone relationships: Observations and model studies with heterogeneous chemistry, J. Geophys. Res., 102, 1561-1569, 1997. 